\section{Infancy}

The first year of life.
${ }^{\prime}$ Centre for Paediatrics, Blizard Institute, Queen Mary University of London, Newark Street, London E1 2AT, UK. ${ }^{2}$ NIHR Biomedical Research Centre and Nuffield Department of Medicine, University of Oxford, Peter Medawar Building, South Parks Road, Oxford OX1 3SY, UK. ${ }^{3}$ Department of Paediatrics, University of Oxford, Peter Medawar Building, South Parks Road, OXford OX1 3SY, UK. Correspondence to P.J.R.G. e-mail:philip.goulder@ paediatrics.ox.ac.uk doi:10.1038/nri3277

\title{
The impact of differential antiviral immunity in children and adults
}

Andrew J. Prendergast ${ }^{1}$, Paul Klenerman ${ }^{2}$ and Philip J. R. Goulder ${ }^{3}$

Abstract | The course of immune maturation has evolved to favour survival at each stage of development in early life. Fetal and neonatal immune adaptations facilitate intrauterine survival and provide early postnatal protection against extracellular pathogens, but they leave infants susceptible to intracellular pathogens such as viruses that are acquired perinatally. This Review focuses on three such pathogens - HIV, hepatitis B virus and cytomegalovirus - and relates the differential impact of these infections in infants and adults to the antiviral immunity that is generated at different ages. A better understanding of age-specific antiviral immunity may inform the development of integrated prevention, treatment and vaccine strategies to minimize the global disease burden resulting from these infections.
The period from fetal development to early infancy is one of vulnerability to maternal transmission of viral infections. Mother-to-child transmission of viruses can occur in utero, at birth (intrapartum) or postnatally. Viral infections acquired at this time are often characterized by higher levels of viral replication, a greater risk of persistent (chronic) infection and more severe disease compared with those acquired in later life. In this Review, we focus on chronic infections with three viruses - HIV, hepatitis B virus (HBV) and cytomegalovirus (CMV) each of which can be acquired through mother-to-child transmission. These viruses cause a substantial burden of disease globally and illustrate the differences between the antiviral immune response in early life and in adulthood. In each case, host control of the virus is highly dependent on age at acquisition. We discuss how differences in antiviral immunity between children and adults fundamentally influence the pathogenesis, time course and clinical outcome of these infections (TABLE 1), and we consider how knowledge of the differential immune responses between early and later life might inform therapeutic strategies to improve the outcome of chronic viral infections in childhood.

\section{Viral transmission and disease burden}

$H I V$. Approximately 34 million people are living with HIV today, of whom 3.4 million are children ${ }^{1}$. Without interventions to prevent mother-to-child transmission, $30-40 \%$ of infants with HIV-positive mothers acquire $\mathrm{HIV}$, and this can occur in utero (5-10\%), intrapartum $(15 \%)$ or postnatally through breastfeeding $(15 \%)^{2}$.
Antiretroviral drugs given to mother and infant decrease transmission substantially. Nonetheless, more than 1,000 infant infections occur daily, predominantly in sub-Saharan Africa, as a result of suboptimal antenatal HIV testing, inadequate coverage of prevention strategies for mother-to-child transmission and the overall benefits of prolonged breastfeeding (that is, in developing countries, breastfeeding reduces the risk of death from gastrointestinal and respiratory tract infections, which is sufficient to outweigh the increased risk of death from HIV transmission by breast milk) ${ }^{1}$.

HIV-infected infants progress to disease more rapidly than adults (TABLE 1). Without treatment, the median times to AIDS and death in adults are approximately 10 and 11 years from infection, respectively ${ }^{3}$. In infected children without treatment, the $\mathrm{CD} 4^{+} \mathrm{T}$ cell count declines rapidly from birth, leading to severe infections and delayed growth and neurological development. Mortality exceeds $50 \%$ by 2 years of age ${ }^{4}$. As with other chronic viral infections, the timing of HIV acquisition affects disease outcome. A recent pooled analysis of 12,112 infants born to HIV-infected women estimated 1-year mortality for perinatally infected children to be $52 \%$, compared with $26 \%$ for postpartum-infected children ${ }^{5}$. In one cohort that distinguished between in utero, intrapartum and postnatal infections, the median times from infection to death were 208, 380 and $>500$ days, respectively ${ }^{6}$. Viral loads are high (with a median of $10^{5}-10^{7}$ copies of viral RNA per ml plasma) in almost all HIV-infected infants, but they tend to be lower in postnatally infected infants compared with those infected in utero or intrapartum, which 
Active immunization

The induction of immunity by immunogens that activate and expand the endogenous immune repertoire. Such immunogens induce antibodies and cell-mediated immunity, as well as immunological memory that might last for decades.

Passive immunization Immunity that is provided rapidly by the transfer of immunoglobulins, the maximal activity of which lasts for approximately $2-3$ weeks before it wanes owing to catabolic destruction. indicates that immune maturation after birth might improve viral control and slow disease progression ${ }^{7,8}$. However, viral loads do not typically reach adult levels $\left(\sim 10^{4}\right.$ copies per $\left.\mathrm{ml}\right)$ until perinatally infected children reach 3-5 years of age ${ }^{9}$ (FIG. 1).

Hepatitis B virus. More than 350 million people are infected with HBV worldwide, and HBV infection accounts for almost half of all cases of cirrhosis, end-stage liver disease and hepatocellular carcinoma ${ }^{10}$. In regions with high endemicity, the major time of infection is early childhood, with mother-to-child transmission at birth having a crucial role ${ }^{10}$. Perinatal HBV acquisition leads to persistent infection in $\sim 90 \%$ of cases, whereas equivalent exposure in adults leads to persistence in $\sim 5 \%$ of cases ${ }^{11}$. The incidence of mother-to-child transmission is markedly reduced by active immunization and passive immunization of the child at birth, providing short-term and long-term protection, respectively, against HBV infection $^{12}$. However, rare cases of intrauterine transmission do occur ${ }^{13}$, depending on the viral load, and effective treatment with antiviral drugs such as lamivudine can reduce this risk further ${ }^{14}$.
The clinical presentation of $\mathrm{HBV}$ infection ranges from asymptomatic infection to fulminant hepatitis, and age at acquisition determines the likelihood of symptoms (TABLE 1). Perinatally infected infants are usually asymptomatic until late adolescence or early adulthood, whereas later acquisition of HBV leads to symptoms such as fever, abdominal pain and jaundice in $5-15 \%$ of children aged $1-5$ years and in $33-50 \%$ of adolescents and adults ${ }^{15}$. Liver damage arises from $\mathrm{CD} 8^{+}$ T cell-mediated destruction of infected hepatocytes (discussed below). The immune response to HBV therefore determines the risk of both viral persistence and clinical disease. Perinatally infected infants have high viral loads and a greater risk of persistence (FIG. 1), but a much longer asymptomatic period ('immunotolerant disease') compared with older children and adults. However, a younger age at infection carries a greater long-term risk of developing hepatocellular carcinoma ${ }^{16}$.

Cytomegalovirus. Congenital CMV infection is the most common congenital infection in the developed world and an important cause of childhood disability ${ }^{17}$. Congenital CMV infection occurs in $0.2-6.2 \%$

\section{Table 1 | Differential clinical outcomes of chronic viral infections in early and later life}

\section{Virus Perinatal infection}

HIV - Rapid disease progression, with a typical time to symptomatic disease of several months in sub-Saharan Africa ${ }^{4}$

- Clinical presentation with pneumonia, septicaemia, gastroenteritis, opportunistic infections (such as CMV infection or Pneumocystis jiroveci pneumonia), failure to thrive, oral candidiasis, persistent diarrhoea and encephalopathy

- More than $50 \%$ mortality within 2 years in the absence of ART ${ }^{4}$

- A small minority $(<5 \%)^{180}$ become long-term non-progressors, with stable $\mathrm{CD} 4^{+} \mathrm{T}$ cell counts, low viral loads and minimal clinical disease, and may only be diagnosed in adolescence

HBV - Acute infection: almost always asymptomatic ${ }^{15}$

- Chronic infection (>90\% of individuals): generally a long 'immunotolerant' phase (up to 20-30 years) with high viral loads but minimal histological changes in the liver; some individuals develop flares of liver disease; long-term risk of cirrhosis, end-stage liver failure and HCC in adulthood ${ }^{125}$

- As an adult, the 5-year survival rate for patients with cirrhosis is $71 \%{ }^{182}$

CMV - Congenital CMV: most infants are asymptomatic at birth; $\sim 11 \%$ have symptoms such as microcephaly, intrauterine growth restriction, hepatosplenomegaly, petechiae, chorioretinitis or jaundice; long-term risks include sensorineural hearing loss, developmental delay and rarely visual loss; permanent sequelae are more likely in those who are symptomatic at birth than in those who are asymptomatic at birth (40-58\% versus $13.5 \%)^{17,18}$

- Postnatal CMV: in extremely pre-term infants, infection can cause symptomatic disease, such as sepsis-like syndrome, hepatitis and pneumonitis, and this has a possible association with long-term neurodevelopmental sequelae ${ }^{20,21}$

- Infection in healthy infants and children is usually asymptomatic, although a mononucleosis-like illness, similar to EBV infection, can occur, with pharyngitis, lymphadenopathy, fever, malaise and hepatomegaly

- Infection in immunocompromised hosts (such as patients with HIV or recipients of solid-organ transplants or haematopoietic stem cell transplants) can cause severe disease, such as hepatitis, pneumonitis, retinitis and gastrointestinal disease

\section{Adult infection}

- Slower disease progression, typically with many years of clinical latency; median time to AIDS is 10 years ${ }^{3}$

- Clinical presentation with pneumonia, septicaemia, skin infections, oral candidiasis and tuberculosis, or with AIDS-defining illnesses such as toxoplasmosis, Pneumocystis jiroveci pneumonia, CMV retinitis, disseminated nontuberculous mycobacterial infections and malignancy

- Approximately $40 \%$ mortality within 10 years in the absence of $\mathrm{ART}^{3}$

- 5-15\% become long-term non-progressors; $<1 \%$ become 'elite controllers', who control the virus to undetectable levels in the absence of ART 181

- Acute infection: may have a prodromal phase with fever, rash and arthralgia; infection is asymptomatic or mild in two-thirds of adults; one-third develop symptomatic hepatitis with fatigue, nausea and jaundice; $1 \%$ develop 'fulminant' hepatitis with acute liver failure ${ }^{125}$

- Chronic infection ( $<5 \%$ of individuals): most individuals are asymptomatic; $15-40 \%$ of adults with chronic disease eventually develop cirrhosis; approximately $2-5 \%$ of those with cirrhosis develop HCC HC $^{125}$

- 5-year survival rate for patients with cirrhosis is $71 \% 182$

- As for healthy infants and children, infection is usually inapparent, but can cause a mononucleosis-like illness

- Severe disease occurs in immunocompromised hosts

$A R T$, antiretroviral therapy; CMV, cytomegalovirus; EBV, Epstein-Barr virus; HBV, hepatitis B virus; HCC, hepatocellular carcinoma. 

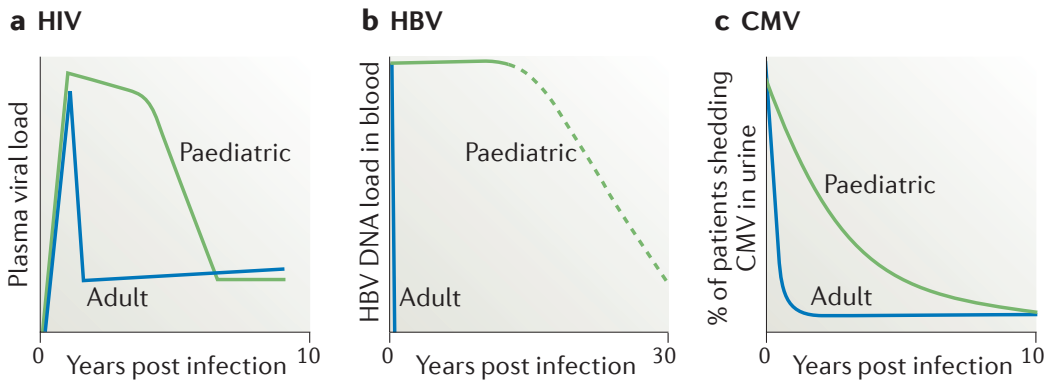

Figure 1 | Differential outcomes of viral infections in early and later life. a A schematic representation of the relative plasma levels of HIV following adult infection (blue line) and paediatric infection (green line) in those children who progress slowly and maintain high $\mathrm{CD} 4^{+} \mathrm{T}$ cell counts despite initial high viraemia. $\mathbf{b} \mid \mathrm{A}$ schematic representation of the time taken to clear hepatitis B virus (HBV) following paediatric infection (green line) and adult infection (blue line). The dashed line for paediatric infection represents the fact that some children do not clear virus at all. $\mathbf{c} \mid$ A schematic representation of the duration of viral shedding in urine following cytomegalovirus (CMV) infection either in early life (green line) or in adult life (blue line).

of live births following maternal CMV reactivation, re-infection or primary infection during pregnancy, causing symptomatic disease in $\sim 11 \%$ of congenitally infected infants and long-term sequelae (such as hearing loss and/or developmental delay) in $50 \%$ of these infants ${ }^{17,18}$. These sequelae are more likely when maternal infection occurs in the first trimester of pregnancy, compared with later in gestation ${ }^{19}$. By contrast, postnatal CMV acquisition through breastfeeding typically does not lead to disease in normal, full-term infants, although in premature or very-low-birth-weight infants it can be symptomatic and possibly associated with long-term motor and cognitive sequelae ${ }^{20,21}$. CMV loads are lower in infants who are infected postnatally than in infants with congenital CMV infection ${ }^{22}$, as is the case for HIV infection. However, CMV infection of immunocompetent infants leads to prolonged viral excretion, which does not occur in adults ${ }^{23}$ (FIG. 1). $\mathrm{CMV}$ is therefore another example of a chronic viral infection for which the outcome is critically dependent on the timing of infection (TABLE 1).

Other viral infections. Other viral infections that also have different outcomes depending on the timing of infection - but that are not discussed in detail here include infections with herpes simplex virus (HSV), varicella zoster virus (VZV), enterovirus, respiratory syncytial virus (RSV) and influenza virus. Most children infected with HSV after the neonatal period have either an asymptomatic infection or a mild cutaneous or orolabial infection, whereas neonates who acquire HSV through contact with infected maternal secretions at birth typically develop severe disseminated or central nervous system disease. Even those infants who initially have localized skin, eye or mouth disease usually progress to systemic infection unless they receive antiviral therapy. Similarly, VZV acquired from a nonimmune mother shortly before or after birth leads to severe neonatal varicella, with an untreated mortality
Enterovirus infections are frequently asymptomatic in older children or adults, but perinatal vertical transmission leads to severe disseminated disease in neonates, and this can be indistinguishable from bacterial sepsis. RSV and influenza virus, similarly to CMV, have a longer period of viral shedding if they are acquired earlier in life. Animal data support these findings: mice infected with lymphocytic choriomeningitis virus (LCMV) in utero or during the first 2 days of life develop a persistent infection, whereas those infected at 2 weeks of age have prolonged viraemia, and those infected as adults clear the virus rapidly ${ }^{24}$. By contrast, after this early neonatal period, several viral infections - notably chickenpox and mumps (BOX 1) - cause markedly less severe disease in childhood than in adulthood. In this Review, we discuss the crucial immunological differences between early and adult life that underpin these differential outcomes of viral infection.

\section{Immune tolerance in early life}

Pregnancy is characterized by the adaptation of both maternal and fetal immune responses towards immunological tolerance. In addition to local mechanisms at the materno-fetal interface ${ }^{25-27}$, the maternal regulatory $\mathrm{T}$ $\left(\mathrm{T}_{\mathrm{Reg}}\right)$ cell pool is expanded to prevent allogeneic $\mathrm{T}$ cells from damaging the fetus ${ }^{28}$. Equally, the fetus needs to tolerate both non-inherited maternal alloantigens and self antigens in utero. Fetal $\mathrm{T}$ cells, which are present after 10 weeks of gestation ${ }^{29}$, are generated from a distinct haematopoietic stem cell population from that used in adult $\mathrm{s}^{30}$ and are highly responsive. Naive $\mathrm{T}$ cells from mid-gestation fetuses show much greater proliferation in a mixed lymphocyte reaction than do naive $\mathrm{T}$ cells from adults, but they tend to differentiate into $\mathrm{CD}^{+} \mathrm{CD} 25^{\text {hiFOXP }}{ }^{+} \mathrm{T}_{\mathrm{Reg}}$ cells following stimulation ${ }^{30}$. In response to non-inherited maternal alloantigens on maternal cells that cross the placenta, the fetus generates $\mathrm{T}_{\text {Reg }}$ cells that persist postnatally ${ }^{31}$. $\mathrm{T}_{\text {Reg }}$ cells constitute up to $15 \%$ of the $\mathrm{CD} 4^{+} \mathrm{T}$ cell pool during fetal life, but they decline to an adult frequency of $\sim 5 \%$ by delivery ${ }^{32}$ (FIG. 2 ). The greater capacity of neonatal innate immune cells to produce interleukin-10 (IL-10) ${ }^{33}$, an anti-inflammatory and immunomodulatory cytokine, reinforces the tolerogenic environment in early life. The fetal immune system is skewed towards $\mathrm{T}$ helper $2\left(\mathrm{~T}_{\mathrm{H}} 2\right)$ cell $^{34}$ and $\mathrm{T}_{\text {Reg }}$ cell $^{13,32}$ populations to avoid pro-inflammatory $\mathrm{T}_{\mathrm{H}} 1$-type responses that could be damaging in utero $^{35}$. Congenital CMV infection, however, results in a shift towards a pro-inflammatory ( $\mathrm{T}_{\mathrm{H}} 1$-type) environment. Indeed, amniotic fluid from second trimester pregnancies with congenital CMV infection has increased levels of pro-inflammatory cytokines (such as tumour necrosis factor (TNF), IL-1 $\beta$, IL-12 and IL-17) compared with amniotic fluid from control pregnancies ${ }^{36}$, and these cytokines can mediate placental and fetal damage ${ }^{37}$. An additional mechanism contributing to congenital CMV disease might be $\mathrm{CD} 4^{+} \mathrm{T}$ cell exhaustion (A. Marchant, personal communication), which could also underlie the striking dichotomy between $\mathrm{CD} 4^{+}$and $\mathrm{CD} 8^{+} \mathrm{T}$ cell responses that is observed in CMV and HIV infection in early life (see below). 


\section{Box 1 | The Goldilocks effect and recent experiments of nature}

Antiviral immune responses in infants or older children are sometimes termed 'impaired' when, more accurately, the response differs both qualitatively and quantitatively from that seen in adults. Although in many respects the neonatal immune response is indeed dampened down compared with the adult response, certain responses are increased in infants. These differences are likely to be the result of Darwinian adaptation that enables the neonatal immune response to be directed mainly against extracellular pathogens. By contrast, protection against intracellular pathogens would largely be provided by maternal antibodies. However, evolutionarily recent changes in human behaviour can expose this time-tested immune strategy to new challenges against which it has not been designed.

An example here would be the immune response to varicella zoster virus (VZV). Infection in infants whose mothers previously had chickenpox leads to very mild symptoms and may even be clinically undetectable. The immune response in the infant is minimal, in part because the infection is attenuated by the presence of maternal antibodies. This weak immune response against VZV carries an increased risk of the reactivation of VZV infection as 'shingles' in adulthood. By contrast, in older children, there is a robust immune response to VZV, characteristic symptoms and signs of chickenpox, and mild illness. In adults with chickenpox, the immune response against VZV is excessive and often leads to significant disease such as pneumonitis and, rarely, death. In Europe, where $90 \%$ of VZV infections occur in children, this system works well. The immune response in children is not too small, as it is in infants, and not too large, as it is in adults, but 'just right'.

Unlike the European setting, where only $2 \%$ of VZV infections occur in adults over 20 years of age, in many tropical countries $50 \%$ of infections occur in this age group. This difference is thought to result from a combination of climatic factors (such as the dramatic seasonal incidence in temperate zones) and cultural factors (such as the occurrence or absence of 'chickenpox parties' for the deliberate exposure of children to VZV). Not only do infected adults suffer severe disease, but $50 \%$ of women risk becoming infected during pregnancy. Disease in the mother can be severe, with a maternal mortality rate of $1 \%$. VZV infection in the first trimester of pregnancy can also cause congenital infection and, if mothers become infected around the time of delivery, neonatal varicella can result, which has a $\sim 30 \%$ risk of fatality.

\section{Innate antiviral immune responses in early life}

Innate antiviral immunity in newborns differs from that in adults ${ }^{35,38}$. Epithelial surfaces in adults are protected by antimicrobial peptides, which can contribute to antiviral defences, but the levels of several antimicrobial peptides are lower in the cord blood of newborns, especially those born prematurely, than in the blood of adults ${ }^{39}$. Innate immune cells - such as monocytes, macrophages and dendritic cells (DCs) - express receptors that recognize pathogen-associated molecular patterns (PAMPs) and trigger the activation of the innate immune response.
Toll-like receptor 3 (TLR3), TLR7 and TLR8, and members of the RIG-I-like receptor (RLR) family, are intrinsic intracellular sensors of viral nucleic acids. Signalling through these pattern-recognition receptors (PRRs) induces the production of various molecules, namely: type I interferons (IFNs); cytokines such as IL-12 and IL-27 that act on natural killer (NK) cells to induce IFN $\gamma$ production; and chemokines such as CXC-chemokine ligand 10 (CXCL10) that are involved in the induction of $\mathrm{CD}^{+} \mathrm{T}$ cells and $\mathrm{T}_{\mathrm{H}} 1$ cells. The importance of TLR signalling in antiviral responses is highlighted in children with mutations in genes controlling the TLR3 signalling pathway, as these children are predisposed to severe encephalitis during primary HSV infection ${ }^{40}$.

TLR stimulation studies reveal quantitative and qualitative differences between neonatal and adult cells. Neonatal plasmacytoid DCs are less polyfunctional than those of adults ${ }^{33}$ and, in response to TLR activation, they produce lower amounts of type I IFNs, which are important for the prevention of viral spread and the induction of antiviral adaptive immune responses ${ }^{41}$. Moreover, in response to TLR ligands, neonatal innate immune cells, as compared with those of adults, produce lower levels of IFN $\gamma$ and IL-12, cytokines that support $\mathrm{T}_{\mathrm{H}} 1$ cell differentiation, and higher levels of IL-6, IL-23 and IL-1 $\beta$, which support $\mathrm{T}_{\mathrm{H}} 17$ cell differentiation ${ }^{33,42}$. This pattern of innate immune responses is amplified in whole blood, as compared with the pattern shown by monocytes and DCs that have been isolated from the blood, suggesting that soluble factors in neonatal serum contribute to the skewing of the cytokine milieu ${ }^{33,43}$. Adenosine, which has immunomodulatory properties and is abundant in neonatal serum, is one factor that contributes to this altered cytokine profile ${ }^{44}$. Taken together, the results indicate that neonatal innate immune defences are skewed towards protection against extracellular bacterial pathogens rather than intracellular bacterial pathogens and viruses, and this presumably provides a survival advantage in early life against rapidly fatal bacterial infections (FIG. 3).

In children who are 1-2 years old, DCs and monocytes are altered in phenotype and function compared with both neonatal and adult cells ${ }^{45}$. Type I IFN production reaches adult levels ${ }^{46}$ and the production of IL-6 and IL-23 (which are $\mathrm{T}_{\mathrm{H}} 17$ cell-polarizing cytokines)

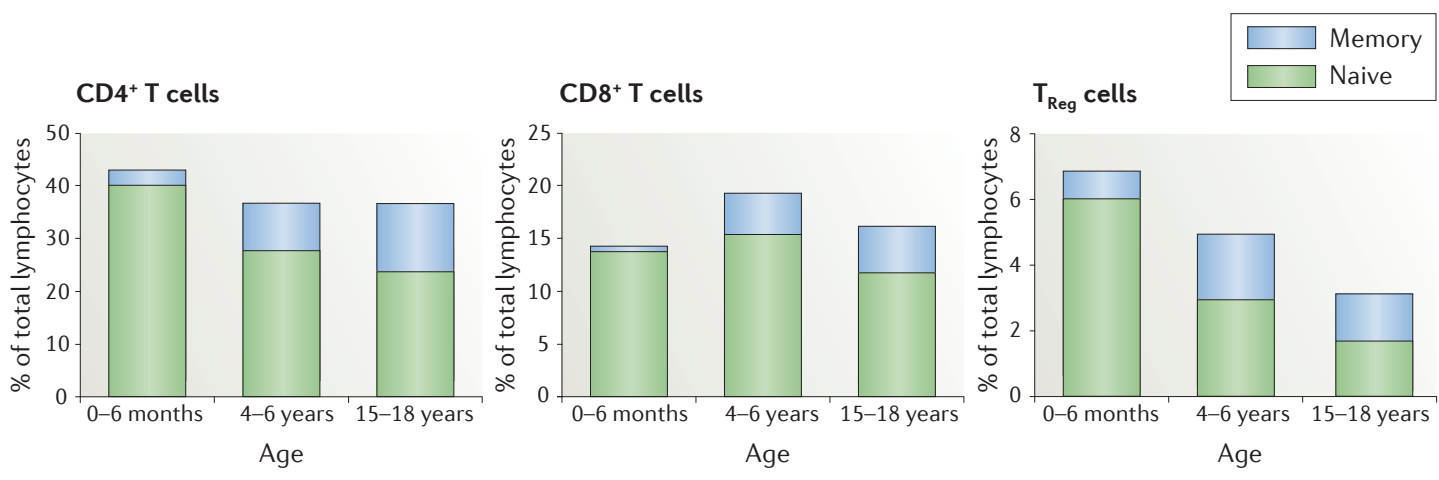

Figure 2 | Changes in lymphocyte subset composition from birth to early adulthood. The figure shows the relative proportions of lymphocytes at birth, 4-6 years of age and 15-18 years of age. The data are adapted from REF. 179. $\mathrm{T}_{\text {Reg }}$ cell, regulatory T cell. 
and of IL-10 is lower than in neonates. Although IL-12 (a $\mathrm{T}_{\mathrm{H}} 1$ cell-polarizing cytokine) production increases ${ }^{46}$, it remains lower than in adults, even into late childhood $^{47}$. Thus, after the neonatal period there is a marked increase in antiviral capacity, owing to increased type I IFN production, and a gradual improvement in responses to intracellular pathogens, although in early childhood these responses remain below adult levels.

The activity of NK cells also differs between neonates and adults, although this aspect of the innate immune response is less well studied in children. NK cells lyse virus-infected cells through the recognition of decreased or absent HLA class I expression or through engagement with IgG-bound target cells (a process known as antibodydependent cell cytotoxicity). NK cells are important early in viral infections, when virus-induced downregulation of HLA expression can hinder the engagement of CD8 ${ }^{+}$ T cells. Although NK cell numbers are similar in newborns and adults ${ }^{48}$, there are differences in the pattern of cell-surface activating and inhibitory receptors ${ }^{49,50}$, the functional consequences of which are unclear. In neonates, NK cell cytotoxic activity against HIV-infected cells is similar to that in adults ${ }^{51,52}$. Non-cytolytic functions of NK cells, such as chemokine-mediated inhibition of HIV replication, are also important in innate antiviral defence. Neonatal NK cells seem to be more effective than adult NK cells at inhibiting the replication of CC-chemokine receptor 5 (CCR5)-tropic HIV strains ${ }^{51}$.

In summary, the differences between neonatal and adult innate immune responses arise mainly as a result of the pattern of cytokine production by innate immune cells in response to PAMPs. In neonates, the levels of IL-12, type I IFNs and IFN $\gamma$ are decreased, whereas the levels of IL-1 $\beta$, IL- 6 , IL-23 and IL-10 are increased compared with the levels in adults (FIG. 3).

\section{Adaptive immune responses in HIV infection}

$H I V$-infected adults. In adults, the high viral load peak $\left(\sim 10^{7}\right.$ copies per $\left.\mathrm{ml}\right)$ that is typical of acute HIV infection declines within a few weeks to a set point, the level of which predicts the speed of disease progression, albeit imperfectly ${ }^{53}$. Studies in humans $s^{54,55}$ and in the simian

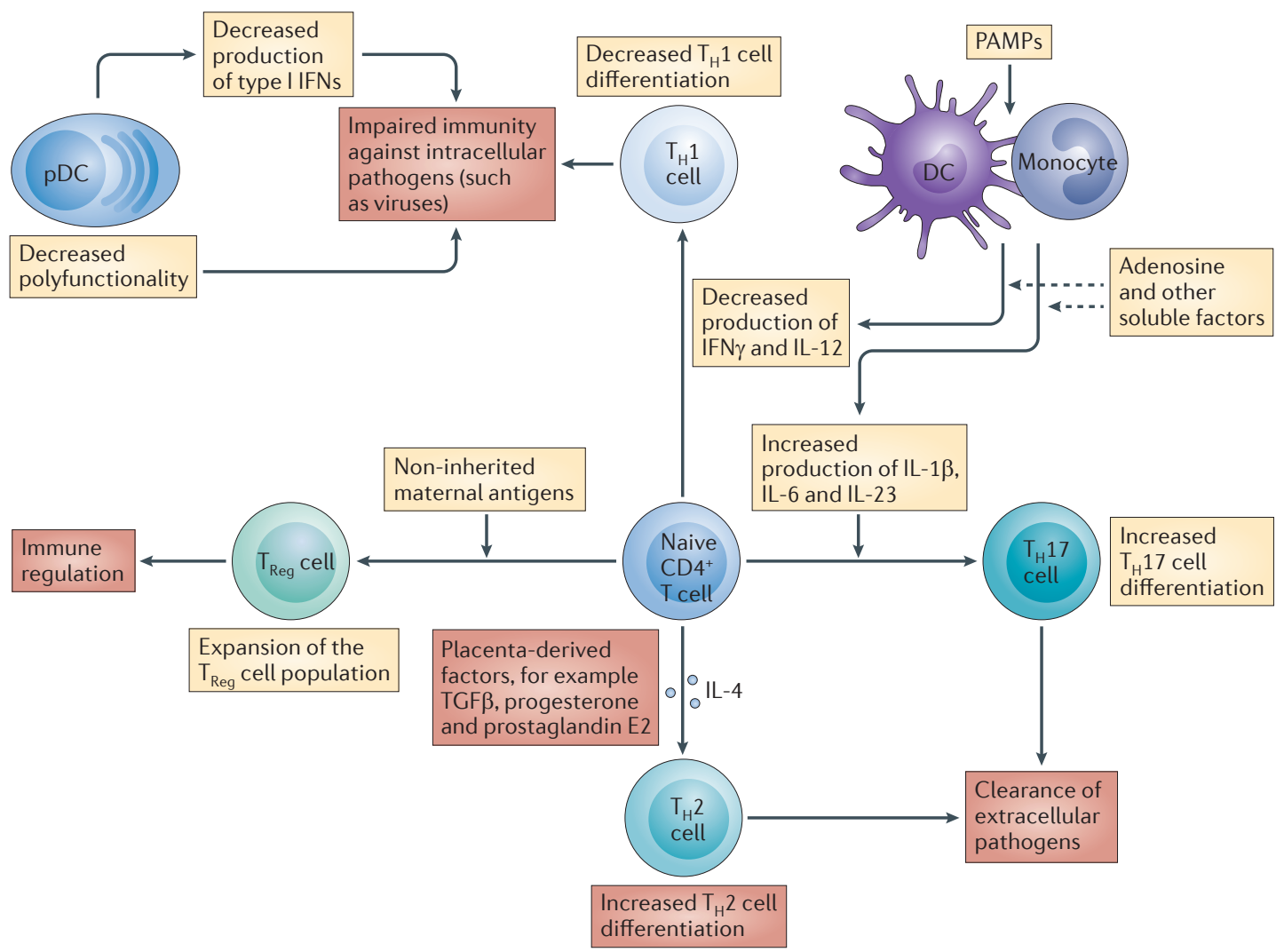

Figure 3 | Differences between innate immunity in early and later life. During fetal life, non-inherited maternal antigens that cross the placenta trigger the expansion of the regulatory $T\left(T_{\text {Reg }}\right)$ cell pool, which constitutes up to $15 \%$ of the peripheral T cell pool during fetal life. In comparison with adult cells, neonatal dendritic cells (DCs) and monocytes have different patterns of cytokine production in response to stimulation by pathogen-associated molecular patterns (PAMPs) through pattern-recognition receptors. Such neonatal cells produce lower levels of interferon- $\gamma$ (IFN $\gamma$ ) and interleukin-12 (IL-12), which support Thelper $1\left(T_{H} 1\right)$ cell differentiation and the clearance of intracellular pathogens such as viruses, and produce higher levels of IL- $1 \beta$, IL- 6 and IL-23, which support $T_{H} 17$ cell differentiation and the clearance of extracellular pathogens. Adenosine and other uncharacterized soluble factors in neonatal plasma seem to exacerbate the skewing of this cytokine milieu. In addition, plasmacytoid DCs (pDCs) in neonates have decreased polyfunctionality and produce lower levels of type I IFNs compared with adult pDCs, which contributes to the impairment of immunity against intracellular pathogens. TGF $\beta$, transforming growth factor- $\beta$. 
immunodeficiency virus (SIV)-macaque model ${ }^{56}$ suggest that HIV-specific CD8 ${ }^{+} \mathrm{T}$ cells can mediate viraemic control. The HLA class I type of an individual has a major impact on HIV disease progression ${ }^{57-59}$. In particular, HLA-B ${ }^{\star} 57$ and HLA-B ${ }^{\star} 27$ are associated with slow progression to AIDS, whereas HLA-B ${ }^{\star} 35$ subtypes are associated with rapid disease progression. The mechanism underlying these HLA class I associations is probably multifactorial, but seems to be related in part to the Gag specificity of the CD8 ${ }^{+} \mathrm{T}$ cell response ${ }^{60-62}$. Evasion of Gag-specific $\mathrm{T}$ cell responses through viral escape mutations can ultimately benefit the host as a result of the consequent reduction in viral replicative capacity (that is, the decreased viral fitness resulting from Gag mutations) $)^{63-65}$.

In addition to their specificity, the functionality of $\mathrm{CD}^{+} \mathrm{T}$ cells is important ${ }^{66-72}$, including their ability to exert a selection pressure on $\mathrm{HIV}^{73,74}$. Other functional measures of $\mathrm{CD}^{+} \mathrm{T}$ cells are also associated with viraemic control. Such measures include proliferative activity $^{70}$ and the capacity to produce multiple cytokines ${ }^{66,67}$, to express perforin ${ }^{70}$ and to load lytic granules ${ }^{71}$. An 'exhausted' phenotype of HIV-specific T cells - similar to that found in mice chronically infected with LCMV ${ }^{75,76}$ - is associated with HIV disease progression ${ }^{68,76-79}$. This $\mathrm{T}$ cell phenotype is characterized by the expression of multiple inhibitory receptors and by decreased proliferation and cytokine production ${ }^{68,77,80,81}$.

$\mathrm{CD}^{+} \mathrm{T}$ cell activity is required for effective $\mathrm{CD} 8^{+}$ $\mathrm{T}$ cell responses against $\mathrm{HIV}^{82,83}$. Although the magnitude of the $\mathrm{CD}^{+} \mathrm{T}$ cell response is not related to viral control $^{84-86}$, as it is for $\mathrm{CD}^{+} \mathrm{T}$ cell responses, a broad Gag-specific $\mathrm{CD}^{+} \mathrm{T}$ cell response is associated with viraemic control, whereas a predominantly Env-specific response is associated with progressive disease ${ }^{86}$.

The role of humoral immunity in controlling established HIV infection is less clear. Neutralizing antibodies arise several months after the initial decline in acute viraemia. Rapid viral escape from neutralizing antibodies means that circulating antibodies are often capable of neutralizing only historical viral quasispecies ${ }^{87}$. However, recent studies in an HIV-infected patient with $\mathrm{B}$ cell lymphoma, who received the CD20-specific monoclonal antibody rituximab and lost viraemic control, reveal the contribution made by neutralizing antibodies in chronic infection ${ }^{88}$. Non-neutralizing antibodies may also provide protection by promoting complement deposition and direct virolysis ${ }^{89}$, by enhancing phagocytosis and by recruiting antiviral effector cells (such as NK cells) to mediate antibody-dependent cell cytotoxicity ${ }^{90}$.

$H I V$-infected infants and older children. In contrast to HIV-infected adults, HIV-infected infants have very high viral loads (typically $10^{5}-10^{7}$ copies per $\mathrm{ml}$ plasma) $)^{8,991-96}$ throughout the first year of life, which decline only slowly with age, at a rate of $0.21 \log _{10}$ copies per $\mathrm{ml}$ per year ${ }^{9}$. There are several immunological reasons for the slow viral decline in children compared with adults (BOX 2). The immune response in early infancy, as described above, is characterized by the preferential induction of $\mathrm{T}_{\mathrm{H}} 2$ and $\mathrm{T}_{\mathrm{H}} 17$ cell responses.
Although $\mathrm{CD}^{+} \mathrm{T}$ cell activity is detectable from birth in HIV-infected infants ${ }^{97-100}$, these responses are initially insufficient to reduce viral load. Furthermore, the maternally transmitted virus may be pre-adapted to the HLA alleles present in the child ${ }^{101-103}$. For example, an HLA-B ${ }^{\star} 27$-positive child cannot generate a crucial HLA-B ${ }^{\star} 27$-restricted Gag-specific response if the HLA-B ${ }^{\star} 27$-positive mother transmits a virus carrying an escape mutation within that Gag epitope. Neither the magnitude nor the breadth of $\mathrm{CD} 8^{+} \mathrm{T}$ cell responses at 1 month of age predicts control of viraemia or mortality within the first year of life ${ }^{104}$, but Gag-specific CD8 ${ }^{+}$ $\mathrm{T}$ cell responses at 3 months of age do predict survival at 12 months ${ }^{105}$. Both the breadth and magnitude of CD8 ${ }^{+}$ T cell responses increase with age ${ }^{99,100,104,106,107}$, with Nef and Env epitopes of HIV-1 being the initial main targets of CD8 ${ }^{+}$T cells ${ }^{99,100,106,107}$. For unknown reasons, Gagspecific responses can increase in magnitude with age substantially more than non-Gag-specific responses ${ }^{106}$. In one study ${ }^{106}$, but not in another ${ }^{107}$, the breadth and magnitude of the Gag-specific CD8 ${ }^{+} \mathrm{T}$ cell response were inversely related to viraemia in HIV-infected children.

As in adults, polyfunctional HIV-specific CD8 ${ }^{+}$ $\mathrm{T}$ cell activity is related to slow disease progression in children ${ }^{108}$, and the upregulation of expression of inhibitory molecules, such as programmed cell death protein 1 (PD1), by $\mathrm{CD}^{+} \mathrm{T}$ cells is also observed in children during HIV infection ${ }^{109,110}$. The ability of $\mathrm{CD} 8^{+} \mathrm{T}$ cells to exert a selection pressure on the virus has not been well studied in children. Viral escape can occur within the first year of life, particularly in epitopes presented by protective HLA alleles ${ }^{102,111-113}$, but the precise timing and consequences of viral escape are unknown. Some infants with protective HLA alleles experience disease progression before making any detectable Gag-specific $\mathrm{CD}^{+} \mathrm{T}$ cell responses, and they therefore derive limited benefit from the expression of those alleles. The narrow $\mathrm{CD}^{+} \mathrm{T}$ cell response in infants can lead to viral escape mutations within epitopes in which mutations are not typically observed in HIV-infected adults, thereby creating an even narrower immune response ${ }^{102}$. Finally, the persistently high levels of viral replication in infants may facilitate the selection of escape mutants with compensatory mutations that increase viral fitness ${ }^{114}$, negating any benefit to the host of selecting escape mutants that have reduced viral replicative capacity.

The most striking contrast between HIV infection in children and adults is the very low levels of $\mathrm{CD} 4^{+}$ $\mathrm{T}$ cell responses that are detectable in children. Most infected infants (of $<1$ year of age) do not have a detectable HIV-specific $\mathrm{CD}^{+} \mathrm{T}$ cell response ${ }^{100,106}$. In the infant SIV-macaque model, suppression of SIV-specific $\mathrm{CD}^{+} \mathrm{T}$ cells occurs due to an expanded $\mathrm{T}_{\mathrm{Reg}}$ cell pool in early life, and depletion of $\mathrm{T}_{\text {Reg }}$ cells is required to detect effector $\mathrm{CD}^{+} \mathrm{T}$ cell responses ${ }^{115}$. When $\mathrm{CD} 4^{+} \mathrm{T}$ cell responses are present, they seem to be important in T cell-mediated control of HIV. One study showed that in HIV-infected human infants of 3-6 months of age, the frequency of Gag-specific CD $4^{+} \mathrm{T}$ cells, but not of $\mathrm{CD}^{+} \mathrm{T}$ cells, was inversely related to viral load ${ }^{105}$. HIVspecific $\mathrm{CD} 4^{+} \mathrm{T}$ cell responses increase with age ${ }^{106,116}$ and, 


\section{Box 2 | Factors contributing to the slow decline of HIV viraemia in paediatric infection}

- Tolerogenic environment: enhanced regulatory T cell activity and increased interleukin-10 (IL-10) production

- Decreased production of type l interferons (IFNs)

- Decreased production of Thelper $1\left(T_{H} 1\right)$ cell-supporting cytokines (such as IL-12 and IFN $\gamma$ ) and increased production of $\mathrm{T}_{\mathrm{H}} 2$ and $\mathrm{T}_{\mathrm{H}} 17$ cell-supporting cytokines (such as IL-6 and IL-23), so T cell-mediated immunity is skewed towards extracellular pathogen clearance

- Low-magnitude $\mathrm{CD} 8{ }^{+} \mathrm{T}$ cell responses with a narrow range of specificities, which predisposes to viral escape mutations

- Inheritance by the child of one HLA haplotype from the mother, which means that the transmitted virus is pre-adapted to at least half of the HLA alleles of the child; if the father previously transmitted HIV to the mother, then the maternally transmitted virus may also be pre-adapted to the paternally inherited HLA alleles of the infant

- HLA alleles associated with mother-to-child transmission are those associated with a high viral set point in adults; therefore, disease-susceptible HLA alleles are enriched in HIV-infected children

- Nef and Env viral antigens are the main targets of CD8 ${ }^{+} T$ cells in infected children; in adults, these specificities of T cells are less effective against the virus than Gag-specific T cells

- Initially undetectable, and subsequently low-magnitude, narrow $\mathrm{CD} 4^{+} \mathrm{T}$ cell responses

- Persistent viraemia facilitates the selection of compensatory viral mutations (which compensate for the reduced viral fitness resulting from $T$ cell escape mutations)

in older children who have not received antiretroviral therapy (ART), there is a strong inverse correlation between the magnitude of $\mathrm{p} 24 \mathrm{Gag}$-specific $\mathrm{CD} 4^{+} \mathrm{T}$ cell responses and viral load ${ }^{107}$. In one study ${ }^{117}$, but not in another ${ }^{107}$, Gag-specific $\mathrm{CD} 4^{+} \mathrm{T}$ cell responses correlated with Gag-specific $\mathrm{CD} 8^{+} \mathrm{T}$ cell activity, which indicates that a strong $\mathrm{T}_{\mathrm{H}}$ cell response of the corresponding specificity might be required to generate effective antiviral $\mathrm{CD} 8^{+} \mathrm{T}$ cells.

The events that bring about the eventual decline in viraemia in paediatric HIV infection remain unknown. Children who manage HIV infection most successfully, and who eventually become 'long-term non-progressors' or 'slow progressors', have lower levels of immune activation in the first weeks of infection ${ }^{118}$. Immune activation also contributes to $\mathrm{CD} 4^{+} \mathrm{T}$ cell depletion in adult infection ${ }^{119}$, as a result of the apoptosis of activated but HIV-uninfected cells ${ }^{120}$, and it is a stronger prognostic indicator of disease outcome than viral load ${ }^{21}$. In the tolerogenic neonatal environment and in the absence of significant $\mathrm{T}_{H}$ cell responses, $\mathrm{CD} 8^{+} \mathrm{T}$ cell activity may be largely irrelevant. In paediatric slow progressors, this phase resembles the situation in natural SIV infection of sooty mangabeys or African green monkeys, in which stable high $\mathrm{CD} 4^{+} \mathrm{T}$ cell counts persist in the setting of high viral loads $\left(>10^{5}\right.$ copies per $\mathrm{ml}$ ) and low immune activation ${ }^{122}$. Depletion of $\mathrm{CD}^{+}$ T cells in sooty mangabeys does not alter the SIV load ${ }^{123}$. However, unlike the SIV-infected sooty mangabeys or African green monkeys, paediatric slow progressors eventually bring the viral load down over time (FIG. 1a) and, also unlike the sooty mangabeys or African green monkeys, this occurs in association with an increasing breadth and magnitude of HIV-specific $\mathrm{CD} 4^{+}$and $\mathrm{CD} 8^{+} \mathrm{T}$ cell responses ${ }^{99,100,104,106,107,116}$.

\section{Adaptive immune responses in $\mathrm{HBV}$ infection}

Hepatitis $B$ virus in adults. HBV infection causes diametrically opposed outcomes in adults and newborns, and this is associated with distinct immune responses. In adults, sustained virological control is achieved through the generation of robust innate, humoral and cellular immune responses; there is evidence for the importance of each from clinical studies and animal models ${ }^{124,125}$. After several weeks of viraemia, without any apparent host response or liver inflammation, the clearance of HBV DNA from plasma is accompanied by the sequential development of antiviral antibodies specific for distinct targets (see below). During the process of viral clearance, a flare of liver inflammation is seen, which can be accompanied by severe liver dysfunction and, rarely, fulminant disease. Although HBV is not clinically detectable in those who have cleared the infection, and such individuals are healthy and non-infectious, viral DNA can be detected in tissues for life ${ }^{126}$.

In contrast to antibody responses in HIV infection, the emergence of antiviral antibodies in HBV infection particularly those specific for the surface antigen and envelope antigen of the virus - is associated with viral control $^{124,127,128}$. The importance of antibodies is probably linked to the relatively invariant nature of the HBV envelope, which provides a reliable target for natural and vaccine-induced humoral immunity. Antibodies contribute to acute clearance of $\mathrm{HBV}$ but also have a longterm role in chronic infection, even in those individuals without circulating virus. This is evident in humans whose $B$ cells are depleted using rituximab, as this treatment can lead to flares of HBV infection, which are sometimes accompanied by severe hepatitis ${ }^{129}$.

Both $\mathrm{CD}^{+}$and $\mathrm{CD} 8^{+} \mathrm{T}$ cell responses have a role in the acute control of HBV and also in immunopathology during chronic disease ${ }^{130}$. The emergence of $\mathrm{CD}^{+} \mathrm{T}$ cell responses immediately precedes the clearance of the virus in individuals studied longitudinally after exposure ${ }^{131}$. There are clear functional, phenotypic and numerical differences in circulating $\mathrm{CD} 4^{+}$ and $\mathrm{CD} 8^{+} \mathrm{T}$ cell responses between individuals with resolved and chronic infection, although cause and effect are not always clear ${ }^{125,132,133}$. It seems likely that, in chronic infection, inflammation in the liver is accompanied by an antiviral $\mathrm{T}$ cell infiltrate that, although insufficient to fully control viral replication (through cytotoxicity or IFN release), nevertheless contributes 
to immune-mediated tissue damage. These ineffective $\mathrm{T}$ cells are characterized by features of T cell exhaustion, including the upregulation of inhibitory receptor expression and of apoptotic pathways ${ }^{132-134}$. However, the nature of the T cell infiltrate in chronic hepatitis is complex, regardless of the aetiology, and includes not only antiviral cells but also a large fraction of non-virus-specific T cells, including NKT cells and mucosa-associated invariant $\mathrm{T}$ cells (MAIT cells) ${ }^{135}$.

Neonatal infection: tolerance, ignorance or immaturity? Although it is well recognized that mother-to-child transmission leads to high rates of HBV persistence, the underlying mechanisms have not been well defined. The failure of neonates to mount typical antibody and $\mathrm{T}$ cell responses to HBV leads to high levels of viraemia with no liver inflammation, and this has been taken as evidence of tolerance ${ }^{136}$. This apparent tolerance is incomplete, as some children develop early clinical disease, which is indicative of an active host response. Furthermore, over longer periods, both $\mathrm{T}$ cell and humoral responses to HBV are typically generated in infants, leading to seroconversion to envelope-antigen-specific antibodies and partial viral control ${ }^{137}$. Nevertheless, failure to mount an effective, or indeed detectable, humoral response is a hallmark of neonatal HBV infection.

A delayed immune response is characteristic of $\mathrm{HBV}$ infection even in adults, who show several weeks of apparent non-responsiveness before an innate immune response is detected, followed eventually by adaptive immune responses and ultimately acute disease and virological control ${ }^{131}$. This is clearly an intrinsic feature of the virus, which is highly host-adapted, having co-evolved with humans for many hundreds, if not thousands, of years ${ }^{138}$. The pre-symptomatic period is difficult to investigate, but it seems that type I IFN responses are delayed, and in addition active suppression occurs through the induction of immunosuppressive IL-10 (REF. 139). Thus, it is currently unclear to what extent the lack of responsiveness is mediated by evasion of innate detection versus active suppression (for example through the action of secreted proteins on TLRs) ${ }^{140,141}$.

These clinical observations and immunological studies indicate that HBV limits or delays the induction of immune responses, but they do not explain the divergent outcomes in adults and neonates. As described above, several features of the neonatal immune system may favour viral replication. A recent study identified low levels of IL-21 secretion in neonates as one such feature ${ }^{142}$. Lack of IL-21 secretion in young mice is an important correlate of failure to control viral replication in a mouse model of human HBV infection, and adult mice failed to control HBV infection when IL-21 signalling was abolished. Similarly, in adult patients, IL-21 is induced during acute resolving disease but not during chronic infection with HBV. The likely source of IL-21 is virus-responsive, liver-homing follicular helper T cells, which are significantly more prevalent in adult mice than in young mice ${ }^{142}$. Of note, responses to $\mathrm{HBV}$ vaccination in neonates (to the same surface antigen as that displayed during natural infection, although the antigen is presented in a different form) are substantial, leading to immediate protection and to long-term memory ${ }^{12,143-146}$. Thus, a lack of IL-21 in this setting may not be limiting if innate immune signalling and antigen presentation are optimal. Indeed, some vaccinated neonates born to $\mathrm{HBV}$-infected mothers have detectable $\mathrm{CD}^{+}$and $\mathrm{CD}^{+} \mathrm{T}$ cell responses to viral polymerase and core proteins that are not present in the vaccine. This indicates that, in the presence of humoral responses induced by a vaccine, robust cellular immunity can help to contain HBV, even in the neonatal period ${ }^{147,148}$.

Overall, HBV infection represents an extreme example of host-virus interactions in the neonatal period, in which apparent tolerance is the norm, with minimal consequences for the host owing to a lack of immunopathology. This is a result of both viral stealth and a lack of innate immune induction, superimposed on a blunted host response and perhaps exaggerated by the tolerogenic environment of the liver. Similar features may apply to hepatitis $\mathrm{C}$ virus (HCV) infection, with the added complications of viral adaptation (as for HIV), although mother-to-child transmission of $\mathrm{HCV}$ is much rarer.

\section{Adaptive immune responses in $\mathrm{CMV}$ infection}

CMV has a very large $(230 \mathrm{~kb})$ genome, which contains multiple genes that interfere with antigen presentation and limit the surface expression of peptide-MHC class I complexes. Despite this, cellular immune responses to CMV are substantial, and some of these CMV genes are probably involved in superinfection rather than immune escape $^{149}$. Infection is lifelong and involves low-level tissue persistence of CMV that is normally contained by continuous active immune surveillance. In mouse models of murine CMV (MCMV) infection and in patients who are immunosuppressed (after transplantation or in late-stage AIDS), loss of this immune surveillance by $\mathrm{T}$ cells and NK cells leads to recrudescence of the virus and severe disease ${ }^{150}$. The observation that perinatal infection is generally not associated with significant pathology suggests that antiviral cellular immune responses to CMV are functional in tissues even during the neonatal period.

Lessons from adult humans and mice. Most CMV-specific immune responses have been studied in adults, during the phase of established viral latency. In this context, immune responses to CMV can be very large, constituting 10\% of the total CD 8 T cell compartment in healthy adults ${ }^{151}$. The size of the CMV-specific CD8 ${ }^{+} \mathrm{T}$ cell pool increases with age $^{152}$. These $\mathrm{T}$ cells are highly differentiated and express markers of continuous or repetitive antigen exposure, but not markers of exhaustion ${ }^{153}$. Thus, they tend to lose expression of co-stimulatory molecules such as CD27 and CD28, express CD57 and re-express CD45RA; such populations of bulk $\mathrm{CD}^{+} \mathrm{T}$ cells are a marker of age. It has been estimated that CMV has an ageing effect on the immune system of approximately 2-3 decades $^{154,155}$. As acute CMV infection is usually clinically silent, few studies have tracked these T cell populations as they emerge, but some analyses of post-transplant infection have revealed the distinct evolution of CMVspecific responses ${ }^{154}$. Studies in mice have tracked the 
development of CMV-specific T cell populations after exposure to CMV. Populations that are dominant in latency are not always immunodominant in acute disease, but may gradually grow over time, a feature termed memory inflation ${ }^{156}$. From such experiments it seems that only some $\mathrm{T}$ cell populations undergo memory inflation; the majority undergo classical memory evolution and are retained as small central memory pools. Memory inflation in mice reflects the known phenotypic and functional features of human responses, and it depends on antigen persistence, continuous turnover of the $\mathrm{T}$ cell pool, T cell help, IL-2 and co-stimulation through OX40 and 4-1BB ligand ${ }^{157}$. Although classical DCs are required for the priming of CMV-specific $\mathrm{T}$ cell responses, nonhaematopoietic cells - which lack constitutive immunoproteasomes and therefore present a different peptide repertoire - are responsible for the long-term maintenance of memory $\mathrm{T}$ cell inflation ${ }^{158}$. This interaction may occur in the lymph nodes, although CMV-specific $\mathrm{T}$ cells tend to accumulate in the tissues, notably the lungs and liver.

$C M V$-specific responses in early life. As discussed above, perinatal infection is typically asymptomatic, although $\mathrm{CMV}$ can cause clinical disease in premature infants $\mathrm{s}^{20,159}$. However, whereas adults typically shed the virus in secretions for weeks to months, virus shedding in children is much more prolonged, and it has been suggested that the urine of infected children aged 1-2 years may provide an important viral reservoir for maternal infection ${ }^{160}$.

$\mathrm{CMV}$-specific $\mathrm{CD} 8^{+} \mathrm{T}$ cell populations in very early life are remarkably similar to those of adults in terms of size, phenotype and function ${ }^{152,153,161}$. Studies in The Gambia, where $62 \%$ of infants are infected by 3 months of age and $85 \%$ by 1 year of age, show that in infants, as in adults, $\mathrm{T}$ cell responses are so large that infection is evident at the level of bulk $\mathrm{CD} 8^{+} \mathrm{T}$ cells, which show changes in the expression level of several differentiation markers. These T cell responses seem to be maintained over time ${ }^{162}$ and are functional, at least in terms of IFN $\gamma$ responses $^{152,162}$.

These data indicate that early $\mathrm{CD} 8^{+} \mathrm{T}$ cell responses to CMV are not impaired in neonatal life, and this is further supported by data from studies in utero. Despite the tolerogenic environment in utero, $\mathrm{CD} 8^{+} \mathrm{T}$ cell responses to CMV are generated during congenital infection ${ }^{163-165}$, and expanded populations of differentiated $\gamma \delta$ T cells can be observed at as early as 21 weeks of gestation ${ }^{166}$. CMVspecific $\mathrm{CD} 8^{+} \mathrm{T}$ cell responses in chronically infected children aged 1.5-4 years are similar in magnitude to those observed in infected adults. However, CMVspecific $\mathrm{CD} 4^{+} \mathrm{T}$ cell responses at this age, when $\mathrm{CMV}$ can still be detected in the urine, are less than $10 \%$ of the magnitude of responses observed in infected adults ${ }^{167}$.

Previously we argued that functional tolerance to HBV during the neonatal period confers an advantage to both host and virus. Could functional immunity to CMV have similar benefits? The immune deviation seen in response to CMV has typically been thought to drive lymphocytes towards immunosenescence and has been associated with various adverse outcomes in the elderly, although this remains controversial ${ }^{155}$. However, emerging data also suggest that, in the early stages of infection, the high number of effector $\mathrm{T}$ cells and the triggering of macrophages in the tissues may have a protective effect against bacterial infection. This has been assessed so far only in mouse models, based on infection with Listeria and Yersinia spp., and the effect may not be very prolonged ${ }^{168,169}$. However, it is tempting to speculate that the rapid immune maturation driven by CMV could reset some of the dampening of innate and adaptive responses described above. As early infection with CMV has been the norm throughout human evolution (indeed, loss of high-level CMV seropositivity in Western populations is a recent experiment of nature), this impact could be viewed as integral to immune maturation, in much the same way that the gut microflora shapes host mucosal immunity.

\section{Implications for therapy}

Given the global impact of viral infections that are acquired in early life, alternative preventive and therapeutic approaches are clearly needed. Interventions to reduce the impact of perinatal viral infections could be targeted at the mother, the infant or the mother-infant dyad.

Maternal interventions. Prevention of primary infection in women is a logical approach to prevent vertical transmission of chronic viral infections, and this is one of the key strategies in HIV prevention programmes for mother-to-child transmission. Vaccination of CMVseronegative women to prevent primary infection during pregnancy would be a cost-effective strategy to reduce congenital CMV infection; however, transmission of CMV to the fetus can occur even in women with preexisting immunity owing to re-infection with distinct strains ${ }^{170}$. Nonetheless, a Phase II trial of a vaccine using recombinant CMV envelope glycoprotein B and a novel MF59 adjuvant showed a vaccine efficacy of 50\% among CMV-seronegative women ${ }^{171}$. Together with data from a recent trial of a CMV DNA vaccine in haematopoietic stem cell transplant recipients ${ }^{172}$, this trial provides promising evidence that effective vaccination against CMV may be an achievable goal in the future.

Interventions among women who are already infected may reduce vertical transmission of viral infections. In the case of HIV infection, effective measures including maternal ART, planned Caesarian section and avoidance of breastfeeding can reduce the probability of mother-to-child transmission to $<1 \%$; however, in many parts of the world, these interventions are not available or feasible. Despite a major drive to eliminate new HIV infections in children by 2015 (REF. 173), paediatric HIV infection remains a major health problem, particularly in sub-Saharan Africa. The number of new infections in children has remained stable over the past 5 years at $\sim 390,000$ per year, and the number of children living with HIV globally is increasing dramatically (FIG. 4). Unless the number of new paediatric infections can be reduced, a rapidly growing paediatric HIV epidemic will develop. 

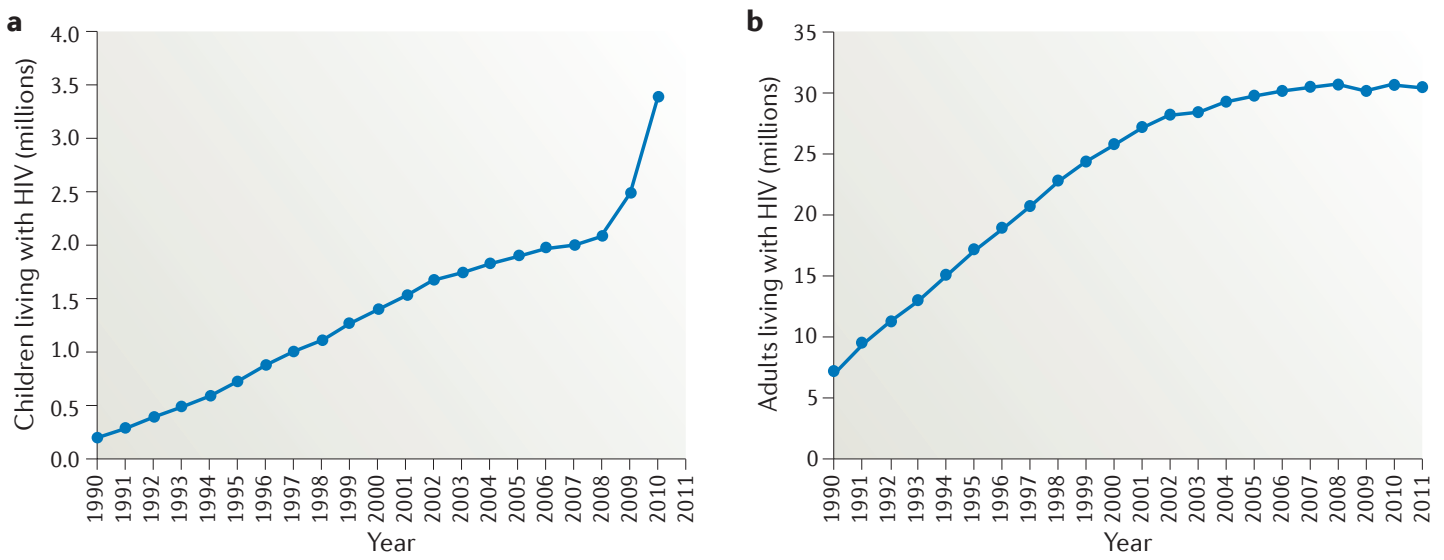

Figure 4 | The number of children and adults living with HIV. The graphs show the number of children (a) and adults (b) living with HIV worldwide. The global data (1990-2011) were published by the World Health Organization (WHO), the United Nations Children's Fund (UNICEF) and the Joint United Nations Programme on HIV and AIDS (UNAIDS) and were obtained from the AVERT Worldwide HIV and AIDS Statistics webpage.

Infant interventions. Immunization at birth is a logical approach for preventing viral infections in early life $\mathrm{e}^{174}$. Globally, birth is an important time of contact with healthcare providers, making it a practical time point at which to administer vaccines. However, in the drive to develop new neonatal vaccines, there is a crucial need to better understand the ontogeny of the immune response to inform vaccine design, the rational choice of adjuvants and the route of administration ${ }^{174}$. In the case of $\mathrm{HBV}$ infection, immunization at birth is the cornerstone of prevention, reducing mother-to-child transmission by $>95 \%{ }^{12}$. Where HBV vaccination coverage is broad, infection in infants results from vaccine failure; this can be due to intrauterine transmission or viral escape mutants.

For infants who become infected with persistent viruses in early life, antiviral treatment may be beneficial. Infants infected with HBV have a long-term risk of cirrhosis, liver failure and hepatocellular carcinoma, and approaches to treatment during childhood with antiviral drugs and IFNs are being evaluated. Treatment of infants with congenital CMV infection using ganciclovir seems to reduce hearing loss and improve neurodevelopmental outcomes $^{175,176}$, but it requires intravenous therapy and is associated with uncertain long-term toxicity. A current trial (ClinicalTrials.gov identifier NCT00466817) is evaluating the efficacies of short (6-week) and long (6-month) courses of the oral prodrug valganciclovir in symptomatic infants. In HIV-infected infants, early treatment with ART substantially reduces disease progression and mortality, but a lifetime of ART from birth is unrealistic because of cost, drug resistance and cumulative toxicity. The case for the development of an effective therapeutic vaccine to enable HIV-infected children to interrupt ART, after successful early treatment, is ever more compelling. In contrast to the situation in HIV-infected adults, thymic activity in infected children enables Gagspecific $\mathrm{CD} 4^{+} \mathrm{T}$ cell responses to be rescued after a period on $\mathrm{ART}^{116}$. However, ART interruption in children is unlikely to be beneficial unless improved antiviral immunity can be induced before ART discontinuation. Given the crucial role of the $\mathrm{T}_{\mathrm{H}}$ cell response described above and the years that it takes for substantial virus-specific $T_{H}$ cell responses to develop in children, together with concerns about the impact of HIV on neurodevelopment in childhood, an optimal time for a vaccine to be used might be in older children, aged 5-10 years, who have been on ART from birth. Co-infection with CMV and HIV also accelerates HIV disease progression ${ }^{177}$. Many breastfed children in developing countries acquire CMV at a very similar time to HIV, which provides another argument in favour of early ART for HIV-infected children. $\mathrm{CMV}$ induces a substantial $\mathrm{T}$ cell response that leads to increased immune activation, which may accelerate HIV disease progression; CMV treatment thus may be beneficial in early life by reducing immune activation, as in adults ${ }^{178}$. Alternatively, the immunostimulatory effects of CMV may accelerate the maturation of the immune response and assist in the subsequent immune control of other viruses, such as HIV.

\section{Conclusion}

In summary, antiviral control in early life - even well into later childhood - is qualitatively and quantitatively different from that of adulthood. This is because of fundamental adaptations, such as the induction of tolerance and robust extracellular immune defences, that have evolved to favour survival in utero and perinatally. Chronic viral infections acquired at this time therefore frequently cause more severe disease than those acquired later. Although effective strategies to reduce mother-to-child transmission of viruses such as HIV and HBV have been developed, these are only successful in certain settings. Efforts to maximize the coverage of prevention strategies for mother-to-child transmission should be prioritized, but it is also necessary to address the consequences in some settings of the failure of these prevention approaches. New strategies should focus on the prevention of maternal infection, neonatal immunization and the use of antiviral therapy in early life. A deeper understanding of the ontogeny of antiviral immunity is critically required to enable the rational design of these interventions. 
1. World Health Organization, UNAIDS \& UNICEF. Global HIV/AIDS response: Progress report 2011 (WHO, 2011).

2. The Working Group on MTCT of HIV. Rates of mother-to-child transmission of HIV-1 in Africa, America and Europe: results of 13 perinatal studies. J. Acquired Immune Defic. Syndr. Hum. Retrovirol. 8, 506-510 (1995)

3. Collaborative Group on AIDS Incubation and HIV Survival, including the CASCADE EU Concerted Action. Time from HIV-1 seroconversion to AIDS and death before widespread use of highly-active antiretrovira therapy: a collaborative re-analysis. Lancet 355 , 1131-1137 (2000)

4. Newell, M. L. et al. Mortality of infected and uninfected infants born to HIV-infected mothers in Africa: a pooled analysis. Lancet 364, 1236-1243 (2004).

5. Becquet, R. et al. Children who acquire HIV infection perinatally are at higher risk of early death than those acquiring infection through breastmilk: a metaanalysis. PLOS ONE 7, e28510 (2012).

6. Marinda, E. et al. Child mortality according to maternal and infant HIV status in Zimbabwe. Pediatr. Infect. Dis. J. 26, 519-526 (2007). This study describes the natural history of perinatal HIV infection in a large cohort of infants prior to the availability of antiretroviral therapy; it demonstrates the importance of the timing of mother-to-child transmission in terms of disease outcome.

7. Biggar, R. J. et al. Virus levels in untreated African infants infected with human immunodeficiency virus type 1. J. Infect. Dis. 180, 1838-1843 (1999).

8. Obimbo, E. M. et al. Pediatric HIV-1 in Kenya: pattern and correlates of viral load and association with mortality. J. Acquired Immune Defic. Syndr. 51, 209-215 (2009)

9. Mclntosh, K. et al. Age- and time-related changes in extracellular viral load in children vertically infected by human immunodeficiency virus. Pediatr. Infect. Dis. J. 15, 1087-1091 (1996).

10. Custer, B. et al. Global epidemiology of hepatitis B virus. J. Clin. Gastroenterol. 38, S158-S168 (2004).

11. Hyams, K. C. Risks of chronicity following acute hepatitis B virus infection: a review. Clin. Infect. Dis. 20, 992-1000 (1995).

12. Beasley, R. P. et al. Prevention of perinatally transmitted hepatitis $B$ virus infections with hepatitis B virus infections with hepatitis $B$ immune globulin and hepatitis B vaccine. Lancet 2, 1099-1102 (1983)

13. Xu, D. Z. et al. Role of placental tissues in the intrauterine transmission of hepatitis B virus. Am J. Obstet. Gynecol. 185, 981-987 (2001)

14. Han, L. et al. A meta-analysis of lamivudine for interruption of mother-to-child transmission of hepatitis B virus. World J. Gastroenterol. 17, 4321-4333 (2011)

15. McMahon, B. J. et al. Acute hepatitis B virus infection relation of age to the clinical expression of disease and subsequent development of the carrier state. J. Infect. Dis. 151, 599-603 (1985).

16. Hsieh, C. C. et al. Age at first establishment of chronic hepatitis B virus infection and hepatocellular carcinoma risk. A birth order study. Am. J. Epidemiol. 136, 1115-1121 (1992).

17. Kenneson, A. \& Cannon, M. J. Review and metaanalysis of the epidemiology of congenital cytomegalovirus (CMV) infection. Rev. Med. Virol. 17, 253-276 (2007)

18. Dollard, S. C., Grosse, S. D. \& Ross, D. S. New estimates of the prevalence of neurological and sensory sequelae and mortality associated with congenital cytomegalovirus infection. Rev. Med. Virol. 17, 355-363 (2007)

19. Pass, R. F., Fowler, K. B., Boppana, S. B., Britt, W. J. $\&$ Stagno, S. Congenital cytomegalovirus infection following first trimester maternal infection: symptoms at birth and outcome. J. Clin. Virol. 35, 216-220 (2006).

20. Bevot, A. et al. Long-term outcome in preterm children with human cytomegalovirus infection transmitted via breast milk. Acta Paediatr. 101, e167-e172 (2012)

21. Wakabayashi, H. et al. Low HCMV DNA copies can establish infection and result in significant symptoms in extremely preterm infants: a prospective study. Am. J. Perinatol. 29, 377-382 (2012).

22. Nijman, J. et al. Urine viral load and correlation with disease severity in infants with congenital or postnatal cytomegalovirus infection. J. Clin. Virol. 54, 121-124 (2012).
23. Pass, R. F., Stagno, S., Britt, W. J. \& Alford, C. A Specific cell-mediated immunity and the natural history of congenital infection with cytomegalovirus. J. Infect. Dis. 148, 953-961 (1983).

24. Belnoue, E., Fontannaz-Bozzotti, P., Grillet, S. Lambert, P. H. \& Siegrist, C. A. Protracted course of lymphocytic choriomeningitis virus WE infection in early life: induction but limited expansion of CD8 effector $\mathrm{T}$ cells and absence of memory CD8 ${ }^{+} \mathrm{T}$ cells. J. Virol. 81, 7338-7350 (2007)

This study demonstrates differential $\mathrm{CD} 8^{+} \mathrm{T}$ cell activity between infants and adults in a murine LCMV model and shows that these differences contribute to persistent viral infection in infants.

25. Makrigiannakis, A et al. Corticotropin-releasing hormone promotes blastocyst implantation and early maternal tolerance. Nature Immunol. 2, 1018-1024 (2001).

26. Roth, I. et al. Human placental cytotrophoblasts produce the immunosuppressive cytokine interleukin 10. J. Exp. Med. 184, 539-548 (1996).

27. Xu, C. et al. A critical role for murine complement regulator Crry in fetomaternal tolerance. Science $\mathbf{2 8 7}$ 498-501 (2000).

28. Aluvihare, V. R., Kallikourdis, M. \& Betz, A. G. Regulatory $T$ cells mediate maternal tolerance to the fetus. Nature Immunol. 5, 266-271 (2004)

29. Haynes, B. F. \& Heinly, C. S. Early human T cell development: analysis of the human thymus at the time of initial entry of hematopoietic stem cells into the fetal thymic microenvironment. J. Exp. Med. 181, 1445-1458 (1995)

30. Mold, J. E. et al. Fetal and adult hematopoietic stem cells give rise to distinct $\mathrm{T}$ cell lineages in humans. Science 330, 1695-1699 (2010).

31. Mold, J. E. et al. Maternal alloantigens promote the development of tolerogenic fetal regulatory T cells in utero. Science 322, 1562-1565 (2008).

This study demonstrates that tolerance to maternal antigens is induced in utero through the induction of fetal CD4 ${ }^{+} \mathrm{CD} 25^{\text {hiFOXP3 }}+$ regulatory T cells.

32. Takahata, Y. et al. CD $25^{+} \mathrm{CD} 4^{+} \mathrm{T}$ cells in human cord blood: an immunoregulatory subset with naive phenotype and specific expression of forkhead box $p 3$ (Foxp3) gene. Exp. Hematol. 32, 622-629 (2004).

33. Kollmann, T. R. et al. Neonatal innate TLR-mediated responses are distinct from those of adults. J. Immunol. 183, 7150-7160 (2009).

This study demonstrates that, compared with those of adults, neonatal innate immune cells preferentially induce $T_{H} 17$ - and $T_{H} 2$-type immune responses to provide protection against extracellular pathogens in early life.

34. Prescott, S. L. et al. Transplacental priming of the human immune system to environmental allergens: universal skewing of initial $\mathrm{T}$ cell responses toward the Th2 cytokine profile. J. Immunol. 160, 4730-4737 (1998)

35. Levy, O. Innate immunity of the newborn: basic mechanisms and clinical correlates. Nature Rev. Immunol. 7, 379-390 (2007)

36. Scott, G. M. et al. Cytomegalovirus infection during pregnancy with maternofetal transmission induces a proinflammatory cytokine bias in placenta and amniotic fluid. J. Infect. Dis. 205, 1305-1310 (2012)

37. Pereira, L. \& Maidji, E. Cytomegalovirus infection in the human placenta: maternal immunity and developmentally regulated receptors on trophoblasts converge. Curr. Top. Microbiol. Immunol. 325 383-395 (2008)

38. Lewis, D. B. \& Wilson, C. B. in Infectious Diseases of the Fetus and Newborn (eds Remington, J.S. et al.) (Elsevier, 2011).

39. Strunk, T. et al. Reduced levels of antimicrobial proteins and peptides in human cord blood plasma. Arch. Dis. Child Fetal Neonatal Ed. 94, F230-F231 (2009)

40. Zhang, S. Y. et al. TLR3 deficiency in patients with herpes simplex encephalitis. Science 317 1522-1527 (2007).

41. Stetson, D. B. $\&$ Medzhitov, R. Type I interferons in host defense. Immunity 25, 373-381 (2006).

42. Belderbos, M. E. et al. Skewed pattern of Toll-like receptor 4-mediated cytokine production in human neonatal blood: low LPS-induced IL-12p70 and high IL-10 persist throughout the first month of life. Clin. Immunol. 133, 228-237 (2009).

43. Belderbos, M. E. et al. Neonatal plasma polarizes TLR4-mediated cytokine responses towards low
IL-12p70 and high IL-10 production via distinct factors. PLOS ONE 7, e33419 (2012).

44. Levy, O. et al. The adenosine system selectively inhibits TLR-mediated TNF- $\alpha$ production in the human newborn. J. Immunol. 177, 1956-1966 (2006).

45. Nguyen, M. et al. Acquisition of adult-like TLR4 and TLR9 responses during the first year of life. PLOS ONE 5, e10407 (2010)

46. Corbett, N. P. et al. Ontogeny of Toll-like receptor mediated cytokine responses of human blood mononuclear cells. PLOS ONE 5, e15041 (2010).

47. Upham, J. W. et al. Development of interleukin-12. producing capacity throughout childhood. Infect. Immun. 70, 6583-6588 (2002)

48. Nakazawa, T., Agematsu, K. \& Yabuhara, A. Later development of Fas ligand-mediated cytotoxicity as compared with granule-mediated cytotoxicity during the maturation of natural killer cells. Immunology 92 180-187 (1997)

49. Sundstrom, Y. et al. The expression of human natural killer cell receptors in early life. Scand. J. Immunol. 66, 335-344 (2007)

50. Dalle, J. H. et al. Characterization of cord blood natural killer cells: implications for transplantation and neonatal infections. Pediatr. Res. 57, 649-655 (2005).

51. Bernstein, H. B., Kinter, A. L, Jackson, R. \& Fauci, A. S. Neonatal natural killer cells produce chemokines and suppress HIV replication in vitro. AIDS Res. Hum. Retroviruses 20, 1189-1195 (2004)

52. Jenkins, M., Mills, J. \& Kohl, S. Natural killer cytotoxicity and antibody-dependent cellular cytotoxicity of human immunodeficiency virus-infected cells by leukocytes from human neonates and adults. Pediatr. Res. 33, 469-474 (1993).

53. Rodriguez, B. et al. Predictive value of plasma HIV RNA level on rate of CD4 T-cell decline in untreated HIV infection. JAMA 296, 1498-1506 (2006).

54. Borrow, P., Lewicki, H., Hahn, B. H., Shaw, G. M. \& Oldstone, M. B. Virus-specific CD8 ${ }^{+}$cytotoxic T-lymphocyte activity associated with control of viremia in primary human immunodeficiency virus type 1 infection. J. Virol. 68, 6103-6110 (1994).

55. Koup, R. A. et al. Temporal association of cellular immune responses with the initial control of viremia in primary human immunodeficiency virus type 1 syndrome. J. Virol. 68, 4650-4655 (1994).

56. Schmitz, J. E. et al. Control of viremia in simian immunodeficiency virus infection by $\mathrm{CD}^{+}$ lymphocytes. Science 283, 857-860 (1999).

57. Carrington, M. \& O'Brien, S. J. The influence of HLA genotype on AIDS. Annu. Rev. Med. 54, 535-551 (2003).

58. Kaslow, R. A. et al. Influence of combinations of human major histocompatibility complex genes on the course of HIV-1 infection. Nature Med. 2, 405-411 (1996).

59. Kiepiela, P. et al. Dominant influence of HLA-B in mediating the potential co-evolution of HIV and HLA. Nature 432, 769-775 (2004)

60. Goulder, P. J et al Novel, cross-restricted, conserved, and immunodominant cytotoxic T lymphocyt epitopes in slow progressors in HIV type 1 infection. AIDS Res. Hum. Retroviruses 12, 1691-1698 (1996).

61. Kiepiela, P. et al. CD8 ${ }^{+}$T-cell responses to different HIV proteins have discordant associations with viral load. Nature Med. 13, 46-53 (2007).

62. Nixon, D. F. et al. HIV-1 Gag-specific cytotoxic T lymphocytes defined with recombinant vaccinia virus and synthetic peptides. Nature 336, 484-487 (1988).

63. Crawford $\mathrm{H}$. et al. Compensatory mutation partially restores fitness and delays reversion of escape mutation within the immunodominant HLA-B*5703-restricted Gag epitope in chronic human immunodeficiency virus type 1 infection. J. Virol. 81 8346-8351 (2007)

64. Martinez-Picado, J. et al. Fitness cost of escape mutations in p24 Gag in association with control of human immunodeficiency virus type 1. J. Virol. 80 , 3617-3623 (2006)

65. Schneidewind, A et al. Escape from the dominant HLA-B27-restricted cytotoxic T-lymphocyte response in Gag is associated with a dramatic reduction in human immunodeficiency virus type 1 replication. J. Virol. 81, 12382-12393 (2007)

66. Akinsiku, O. T., Bansal, A., Sabbaj, S., Heath, S. L. \& Goepfert, P. A. Interleukin-2 production by polyfunctional HIV-1-specific CD8 T cells is associated with enhanced viral suppression. J. Acquir. Immune Defic. Syndr. 58, 132-140 (2011).

67. Betts, M. R et al. HIV nonprogressors preferentially maintain highly functional HIV-specific CD8 + T cells. Blood 107, 4781-4789 (2006). 
68. Day, C. L. et al. PD-1 expression on HIV-specific T cells is associated with T-cell exhaustion and disease progression. Nature 443, 350-354 (2006)

69. Ferrando-Martinez, S. et al. Differential Gag-specific polyfunctional T cell maturation patterns in HIV-1 elite controllers. J. Virol. 86, 3667-3674 (2012).

70. Migueles, S. A. et al. HIV-specific CD8 ${ }^{+} \mathrm{T}$ cell proliferation is coupled to perforin expression and is maintained in nonprogressors. Nature Immunol. 3, 1061-1068 (2002).

71. Migueles, S. A. et al. Lytic granule loading of CD8 ${ }^{+}$ $\mathrm{T}$ cells is required for HIV-infected cell elimination associated with immune control. Immunity 29 , 1009-1021 (2008)

72. Yamamoto, T. et al. Virus inhibition activity of effector memory $\mathrm{CD}^{+} \mathrm{T}$ cells determines simian immunodeficiency virus load in vaccinated monkeys after vaccine breakthrough infection. J. Virol. 86, 5877-5884 (2012).

73. Kloverpris, H. N. et al. HLA-B*57 micropolymorphism shapes HLA allele-specific epitope immunogenicity, selection pressure, and HIV immune control. J. Virol. 86, 919-929 (2012)

74. Matthews, P. C. et al. Central role of reverting mutations in HLA associations with human immunodeficiency virus set point. J. Virol. 82, 8548-8559 (2008).

75. Blackburn, S. D. et al. Coregulation of $\mathrm{CD}^{+} \mathrm{T}$ cell exhaustion by multiple inhibitory receptors during chronic viral infection. Nature Immunol. 10, 29-37 (2009).

76. Jin, H. T. et al. Cooperation of Tim-3 and PD- 1 in CD8 T-cell exhaustion during chronic viral infection. Proc. Natl Acad. Sci. USA 107, 14733-14738 (2010)

77. Jones, R. B. et al. Tim-3 expression defines a novel population of dysfunctional T cells with highly elevated frequencies in progressive HIV-1 infection. J. Exp. Med. 205, 2763-2779 (2008).

78. Barber, D. L. et al. Restoring function in exhausted CD8 T cells during chronic viral infection. Nature 439 682-687 (2006)

79. Velu, V. et al. Enhancing SIV-specific immunity in vivo by PD-1 blockade. Nature 458, 206-210 (2009).

80. Kaufmann, D. E. et al. Upregulation of CTLA-4 by $\mathrm{HIV}$-specific $\mathrm{CD}^{+}{ }^{+} \mathrm{T}$ cells correlates with disease progression and defines a reversible immune dysfunction. Nature Immunol. 8, 1246-1254 (2007).

81. Trautmann, L. et al. Upregulation of PD-1 expression on HIV-specific CD8 ${ }^{+} \mathrm{T}$ cells leads to reversible immune dysfunction. Nature Med. 12, 1198-1202 (2006).

82. Shedlock, D. J. \& Shen, H. Requirement for CD4 T cell help in generating functional CD8 T cell memory. Science 300, 337-339 (2003)

83. Sun, J. C. \& Bevan, M. J. Defective CD8 T cell memory following acute infection without CD4 T cell help. Science 300, 339-342 (2003).

84. Betts, M. R. et al. Analysis of total human immunodeficiency virus (HIV)-specific $\mathrm{CD}^{+}$and CD8+ T-cell responses: relationship to viral load in untreated HIV infection. J. Virol. 75, 11983-1199 (2001).

85. Pitcher, C. J. et al. HIV-1-specific CD4 ${ }^{+} \mathrm{T}$ cells are detectable in most individuals with active HIV-1 infection, but decline with prolonged viral suppression. Nature Med. 5, 518-525 (1999).

86. Ranasinghe, S. et al. HIV-specific CD4 T cell responses to different viral proteins have discordant associations with viral load and clinical outcome. J. Virol. 86, 277-283 (2012)

87. Wei, X. et al. Antibody neutralization and escape by HIV-1, Nature 422, 307-312 (2003).

88. Huang, K. H. et al. B-cell depletion reveals a role for antibodies in the control of chronic HIV-1 infection. Nature Commun. 1, 102 (2010).

89. Burton, D. R. Antibodies, viruses and vaccines. Nature Rev. Immunol. 2, 706-713 (2002).

90. Hessell, A. J. et al. Fc receptor but not complement binding is important in antibody protection against HIV. Nature 449, 101-104 (2007).

91. Abrams, E. J. et al. Association of human immunodeficiency virus (HIV) load early in life with disease progression among HIV-infected infants. New York City Perinatal HIV Transmission Collaborative Study Group. J. Infect. Dis. 178, 101-108 (1998).

92. Biggar, R. J et al. Viral levels in newborn African infants undergoing primary HIV-1 infection. AIDS 15 , 1311-1313 (2001)

93. Dickover, R. E. et al. Early prognostic indicators in primary perinatal human immunodeficiency virus type 1 infection: importance of viral RNA and the timing of transmission on long-term outcome. J. Infect. Dis. 178, 375-387 (1998).
94. Mphatswe, W. et al. High frequency of rapid immunological progression in African infants infected in the era of perinatal HIV prophylaxis. AIDS 21 1253-1261 (2007)

95. Rouet, F. et al. Pediatric viral human immunodeficiency virus type 1 RNA levels, timing of infection, and disease progression in African HIV-1-infected children. Pediatrics 112, e289 (2003).

96. Shearer, W. T. et al. Viral load and disease progression in infants infected with human immunodeficiency virus type 1. Women and Infants Transmission Study Group. N. Engl. J. Med. 336, 1337-1342 (1997).

97. Luzuriaga, K. et al. HIV-1-specific cytotoxic T lymphocyte responses in the first year of life. J. Immunol. 154, 433-443 (1995).

98. Scott, Z. A. et al. Infrequent detection of HIV-1-specific, but not cytomegalovirus-specific, CD8 ${ }^{+} \mathrm{T}$ cell responses in young HIV-1-infected infants. J. Immunol. 167, 7134-7140 (2001).

99. Shalekoff, S. et al. Identification of human immunodeficiency virus- 1 specific $\mathrm{CD} 8^{+}$and $\mathrm{CD} 4$ $\mathrm{T}$ cell responses in perinatally-infected infants and their mothers. AIDS 23, 789-798 (2009).

100. Thobakgale, C. F. et al. Human immunodeficiency virus-specific $\mathrm{CD}^{+}{ }^{+} \mathrm{T}$-cell activity is detectable from birth in the majority of in utero-infected infants. J. Virol. 81, 12775-12784 (2007). This study shows that, even on the first day of life, HIV-specific CD8 ${ }^{+} \mathrm{T}$ cells can be detected in perinatally infected infants.

101. Goulder, P. J. et al. Evolution and transmission of stable CTL escape mutations in HIV infection. Nature 412, 334-338 (2001).

102. Pillay, T. et al. Unique acquisition of cytotoxic T-lymphocyte escape mutants in infant human immunodeficiency virus type 1 infection. J. Virol. 79, 12100-12105 (2005)

103. Thobakgale, C. F. et al. Impact of HLA in mother and child on paediatric HIV-1 disease progression. J. Virol. 83, 10234-10244 (2009).

104. Lohman, B. L. et al. Longitudinal assessment of human immunodeficiency virus type 1 (HIV-1)-specific $\gamma$ interferon responses during the first year of life in HIV-1-infected infants. J. Virol. 79, 8121-8130 (2005).

105. Nqoko, B. et al. HIV-specific Gag responses in early infancy correlate with clinical outcome and inversely with viral load. AIDS Res. Hum. Retroviruses $\mathbf{2 7}$ 1311-1316 (2011).

106. Huang, S. et al. Deficiency of HIV-Gag-specific T cells in early childhood correlates with poor viral containment. J. Immunol. 181, 8103-8111 (2008).

107. Prendergast, A. et al. Gag-specific CD4 ${ }^{+}$T-cell responses are associated with virological control of paediatric HIV-1 infection. AIDS 25, 1329-1331 (2011)

108. Thobakgale, C. F. et al. Short communication: CD8 ${ }^{+}$ $\mathrm{T}$ cell polyfunctionality profiles in progressive and nonprogressive pediatric HIV type 1 infection. AIDS Res. Hum. Retroviruses 27, 1005-1012 (2011)

109. Prendergast, A. et al. Factors influencing T cell activation and programmed death 1 expression in HIV-infected children. AIDS Res. Hum. Retroviruses 28, 465-468 (2012).

110. Ssewanyana, I. et al. The distribution and immune profile of T cell subsets in HIV-infected children from Uganda. AIDS Res. Hum. Retroviruses 25, 65-71 (2009).

111. Leslie, A. et al. Transmission and accumulation of CTL escape variants drive negative associations between HIV polymorphisms and HLA. J. Exp. Med. 201 891-902 (2005).

112. Prado, J. G. et al. Replicative capacity of human immunodeficiency virus type 1 transmitted from mother to child is associated with pediatric disease progression rate. J. Virol. 84, 492-502 (2010).

113. Sanchez-Merino, V., Nie, S. \& Luzuriaga, K. HIV-1-specific CD8 ${ }^{+} \mathrm{T}$ cell responses and viral evolution in women and infants. J. Immunol. 175, 6976-6986 (2005)

114. Tang, Y. et al. Correlates of spontaneous viral contro among long-term survivors of perinatal HIV-1 infection expressing human leukocyte antigen-B57. AIDS 24 , 1425-1435 (2010)

115. Hartigan-O'Connor, D. J., Abel, K. \& McCune, J. M. Suppression of SIV-specific CD4 ${ }^{+} \mathrm{T}$ cells by infant but not adult macaque regulatory $T$ cells: implications for SIV disease progression. J. Exp. Med. 204 2679-2692 (2007) This study shows that $T_{\text {Reg }}$ cells in infant, but not adult, macaques suppress SIV-specific $\mathrm{CD4}{ }^{+} \mathrm{T}$ cell responses, which can only be detected after the depletion of $\mathrm{T}_{\text {Reg }}$ cells.
116. Feeney, M. E. et al. Reconstitution of virus-specific CD4 proliferative responses in pediatric HIV-1 infection. J. Immunol. 171, 6968-6975 (2003).

117. Ssewanyana, I. et al. Profile of T cell immune responses in HIV-infected children from Uganda. J. Infect. Dis. 196, 1667-1670 (2007).

118. Paul, M. E. et al. Predictors of immunologic long-term nonprogression in HIV-infected children: implications for initiating therapy. J. Allergy Clin. Immunol. 115 848-855 (2005).

119. Hazenberg M. D et al Persistent immune activation in HIV-1 infection is associated with progression to AIDS. AIDS 17, 1881-1888 (2003).

120. Finkel, T. H. et al. Apoptosis occurs predominantly in bystander cells and not in productively infected cells of HIV- and SIV-infected lymph nodes. Nature Med. 1, 129-134 (1995).

121. Giorgi, J. V. et al. Shorter survival in advanced human immunodeficiency virus type 1 infection is more closely associated with $\mathrm{T}$ lymphocyte activation than with plasma virus burden or virus chemokine coreceptor usage. J. Infect. Dis. 179, 859-870 (1999).

122. Silvestri, G. et al. Nonpathogenic SIV infection of sooty mangabeys is characterized by limited bystander immunopathology despite chronic high-level viremia. Immunity 18, 441-452 (2003).

123. Barry, A. P. et al. Depletion of CD $8^{+}$cells in sooty mangabey monkeys naturally infected with simian immunodeficiency virus reveals limited role for immune control of virus replication in a natural host species. J. Immunol. 178, 8002-8012 (2007)

124. Chisari, F. V. \& Ferrari, C. Hepatitis B virus immunopathogenesis. Annu. Rev. Immunol. 13 29-60 (1995)

125. Nebbia, G., Peppa, D. \& Maini, M. K. Hepatitis B infection: current concepts and future challenges. OJM 105, 109-113 (2012).

126. Rehermann, B., Ferrari, C., Pasquinelli, C. \& Chisari, F. V. The hepatitis B virus persists for decades after patients' recovery from acute viral hepatitis despite active maintenance of a cytotoxic T-lymphocyte response. Nature Med. 2, 1104-1108 (1996).

127. Ganem, D. \& Prince, A. M. Hepatitis B virus infection - natural history and clinical consequences. N. Engl. J. Med. 350, 1118-1129 (2004).

128. Liang, T. J. Hepatitis B: the virus and disease. Hepatology 49, S13-S21 (2009)

129. Koo, Y. X. et al. Risk of hepatitis B virus (HBV) reactivation in hepatitis $B$ surface antigen negative/ hepatitis $\mathrm{B}$ core antibody positive patients receiving rituximab-containing combination chemotherapy without routine antiviral prophylaxis. Ann. Hematol. 90, 1219-1223 (2011)

130. Yang, P. L. et al. Immune effectors required for hepatitis B virus clearance. Proc. Natl Acad. Sci. USA 107, 798-802 (2010).

131. Webster, G. J. et al. Incubation phase of acute hepatitis B in man: dynamic of cellular immune mechanisms. Hepatology 32, 1117-1124 (2000)

132. Das, A et al. Functional skewing of the global CD8 $\mathrm{T}$ cell population in chronic hepatitis B virus infection J. Exp. Med. 205, 2111-2124 (2008).

133. Lopes, A. R. et al. Bim-mediated deletion of antigenspecific CD8 T cells in patients unable to control HBV infection. J. Clin. Invest. 118, 1835-1845 (2008).

134. Schurich, A. et al. Role of the coinhibitory receptor cytotoxic T lymphocyte antigen-4 on apoptosis-prone CD8 $\mathrm{T}$ cells in persistent hepatitis $\mathrm{B}$ virus infection. Hepatology 53, 1494-1503 (2011).

135. Walker, L. J. et al. Human MAIT and CD8aa cells develop from a pool of type-17 precommitted CD8 ${ }^{+}$ T cells. Blood 119, 422-433 (2012).

136. Heathcote, E. J. Demography and presentation of chronic hepatitis B virus infection. Am. J. Med. 121 S3-S11 (2008)

137. Chang, M. H. et al. The significance of spontaneous hepatitis $\mathrm{B}$ e antigen seroconversion in childhood with special emphasis on the clearance of hepatitis B e antigen before 3 years of age. Hepatology 22, 1387-1392 (1995).

138. Zhou, Y. \& Holmes, E. C. Bayesian estimates of the evolutionary rate and age of hepatitis $\mathrm{B}$ virus. J. Mol. Evol. 65, 197-205 (2007).

139. Dunn, C. et al. Temporal analysis of early immune responses in patients with acute hepatitis B infection. Gastroenterology 137, 1289-1300 (2009).

140. Wieland, S., Thimme, R., Purcell, R. H. \& Chisari, F. V. Genomic analysis of the host response to hepatitis B virus infection. Proc. Natl Acad. Sci. USA 101, 6669-6674 (2004). 
141. Vincent, I. E. et al. Hepatitis B virus impairs TLR9 expression and function in plasmacytoid dendritic cells. PLoS ONE 6, e26315 (2011).

142. Publicover, J. et al. IL-21 is pivotal in determining agedependent effectiveness of immune responses in a mouse model of human hepatitis B. J. Clin. Invest. 121, 1154-1162 (2011). This study provides mechanistic evidence for the role of IL-21 in determining long-term outcome after HBV infection.

143. Barin, F. et al. Immune response in neonates to hepatitis B vaccine. Lancet 1, 251-253 (1982).

144. Su, W. J. et al. Effect of age on the incidence of acute hepatitis B after 25 years of a universal newborn hepatitis B immunization program in Taiwan. J. Infect. Dis. 205, 757-762 (2012)

145. Wong, V. C. et al. Prevention of the HBsAg carrier state in newborn infants of mothers who are chronic carriers of $\mathrm{HBsAg}$ and $\mathrm{HBeAg}$ by administration of hepatitis-B vaccine and hepatitis-B immunoglobulin. Double-blind randomised placebo-controlled study. Lancet 1, 921-926 (1984).

146. Wu, Q. et al. Antibody levels and immune memory 23 years after primary plasma-derived hepatitis B vaccination: results of a randomized placebocontrolled trial cohort from China where endemicity is high. Vaccine 29, 2302-2307 (2011).

147. Koumbi, L. et al. Hepatitis B-specific T helper cell responses in uninfected infants born to $\mathrm{HBsAg}^{+} / \mathrm{HBeAg}$ mothers. Cell. Mol. Immunol. 7, 454-458 (2010).

148. Komatsu, H. et al. Cellular immunity in children with successful immunoprophylactic treatment for motherto-child transmission of hepatitis B virus. BMC Infect. Dis. 10, 103 (2010)

149. Hansen, S. G et al. Evasion of CD8 ${ }^{+}$T cells is critical for superinfection by cytomegalovirus. Science $\mathbf{3 2 8}$ 102-106 (2010).

150. Polic, B. et al. Hierarchical and redundant lymphocyte subset control precludes cytomegalovirus replication during latent infection. J. Exp. Med. 188, 1047-1054 (1998).

151. Sylwester, A. W. et al. Broadly targeted human cytomegalovirus-specific $\mathrm{CD} 4^{+}$and $\mathrm{CD} 8^{+} \mathrm{T}$ cells dominate the memory compartments of exposed subjects. J. Exp. Med. 202, 673-685 (2005).

152. Komatsu, H. et al. Large scale analysis of pediatric antiviral $\mathrm{CD} 8+\mathrm{T}$ cell populations reveals sustained, functional and mature responses. Immun. Ageing 3, 11 (2006)

153. Appay, V. et al. Memory CD8 ${ }^{+} \mathrm{T}$ cells vary in differentiation phenotype in different persistent virus infections. Nature Med. 8, 379-385 (2002).

154. Northfield, J., Lucas, M., Jones, H., Young, N. T. \& Klenerman, P. Does memory improve with age? CD85j (ILT-2/LIR-1) expression on CD8 T cells correlates with 'memory inflation' in human cytomegalovirus infection. Immunol. Cell Biol. 83, 182-188 (2005).

155. Wills, M. et al. Report from the second cytomegalovirus and immunosenescence workshop. Immun. Ageing 8, 10 (2011).

156. Karrer, U. et al. Memory inflation: continuous accumulation of antiviral $\mathrm{CD} 8+\mathrm{T}$ cells over time. J. Immunol. 170, 2022-2029 (2003).

157. O'Hara, G. A., Welten, S. P., Klenerman, P. \& Arens, R. Memory $T$ cell inflation: understanding cause and effect. Trends Immunol. 33, 84-90 (2012).
158. Torti, N., Walton, S. M., Brocker, T., Rulicke, T $\delta$ Oxenius, A. Non-hematopoietic cells in lymph nodes drive memory CD8 T cell inflation during murine cytomegalovirus infection. PLoS Pathog. 7, e1002313 (2011).

This study provides a demonstration of the anatomical and cellular requirements for memory inflation in CMV infection.

159. Ehlinger, E. P. et al. Maternal cytomegalovirus-specific immune responses and symptomatic postnatal cytomegalovirus transmission in very low-birth-weight preterm infants. J. Infect. Dis. 204, 1672-1682 (2011).

160. Cannon, M. J., Hyde, T. B. \& Schmid, D. S. Review of cytomegalovirus shedding in bodily fluids and relevance to congenital cytomegalovirus infection. Rev. Med. Virol. 21, 240-255 (2011).

161. Miles, D. J. et al. Cytomegalovirus infection in Gambian infants leads to profound CD8 T-cell differentiation. J. Virol. 81, 5766-5776 (2007).

162. Miles, D. J. et al. Maintenance of large subpopulations of differentiated CD8 T-cells two years after cytomegalovirus infection in Gambian infants PLOS ONE 3, e2905 (2008).

163. Elbou Ould, M. A. et al. Cellular immune response of fetuses to cytomegalovirus. Pediatr. Res. $\mathbf{5 5}$ 280-286 (2004).

164. Marchant, A. et al. Mature CD8 + T lymphocyte response to viral infection during fetal life. J. Clin. Invest. 111, 1747-1755 (2003). This study provides the first demonstration of effector $\mathrm{CD}^{+} \mathrm{T}$ cell responses specific for $\mathrm{CMV}$ generated during prenatal life.

165. Pedron, B. et al. Comparison of $\mathrm{CD}^{+} \mathrm{T}$ cell responses to cytomegalovirus between human fetuses and their transmitter mothers. J. Infect. Dis. 196, 1033-1043 (2007)

166. Vermijlen, D. et al. Human cytomegalovirus elicits fetal $\gamma \delta \mathrm{T}$ cell responses in utero. J. Exp. Med. 207 , 807-821 (2010).

167. Tu, W. et al. Persistent and selective deficiency of $\mathrm{CD} 4^{+} \mathrm{T}$ cell immunity to cytomegalovirus in immunocompetent young children. J. Immunol. 172 3260-3267 (2004)

168. Barton, E. S. et al. Herpesvirus latency confers symbiotic protection from bacterial infection. Nature 447, 326-329 (2007).

169. Yager, E. J. et al. $\gamma$-Herpesvirus-induced protection against bacterial infection is transient. Viral Immunol. 22, 67-72 (2009)

170. Boppana, S. B., Rivera, L. B., Fowler, K. B., Mach, M. \& Britt, W. J. Intrauterine transmission of cytomegalovirus to infants of women with preconceptional immunity. N. Engl. J. Med. 344 1366-1371 (2001)

171. Pass, R. F. et al. Vaccine prevention of maternal cytomegalovirus infection. N. Engl. J. Med. 360 1191-1199 (2009)

172. Kharfan-Dabaja, M. A. et al. A novel therapeutic cytomegalovirus DNA vaccine in allogeneic haemopoietic stem-cell transplantation: a randomised, double-blind, placebo-controlled, phase 2 trial. Lancet Infect. Dis. 12, 290-299 (2012).

173. UNAIDS. Countdown to zero: Global plan towards elimination of new HIV infections among children by 2015 and keeping their mothers alive (UNAIDS, 2011).
174. Sanchez-Schmitz, G. \& Levy, O. Development of newborn and infant vaccines. Sci. Transl. Med. 3, 90ps27 (2011)

175. Kimberlin, D. W. et al. Effect of ganciclovir therapy on hearing in symptomatic congenital cytomegalovirus disease involving the central nervous system: randomized, controlled trial. J. Pediatr. 143, 16-25 (2003).

176. Oliver, S. et al. Neurodevelopmental outcomes following ganciclovir therapy in symptomatic congenital cytomegalovirus infections involving the central nervous system. J. Clin. Virol. 46 (Suppl. 4), S22-S26 (2009)

177. Kovacs, A. et al. Cytomegalovirus infection and HIV-1 disease progression in infants born to HIV-1-infected women. Pediatric Pulmonary and Cardiovascular Complications of Vertically Transmitted HIV Infection Study Group. N. Engl. J. Med. 341, 77-84 (1999). This study demonstrates the importance of viral co-infections in early life: infants infected with both HIV and CMV had higher rates of disease progression by 18 months of age than infants infected only with HIV.

178. Hunt, P. W. et al. Valganciclovir reduces T cell activation in HIV-infected individuals with incomplete CD4 ${ }^{+} \mathrm{T}$ cell recovery on antiretroviral therapy. J. Infect. Dis. 203, 1474-1483 (2011).

179. van Gent, R. et al. Refined characterization and reference values of the pediatric $\mathrm{T}$ - and B-cell compartments. Clin. Immunol. 133, 95-107 (2009).

180. Warszawski, J. et al. Long-term nonprogression of HIV infection in children: evaluation of the ANRS prospective French pediatric cohort. Clin. Infect. Dis. 45, 785-794 (2007)

181. Deeks, S. G. \& Walker, B. D. Human immunodeficiency virus controllers: mechanisms of durable virus control in the absence of antiretroviral therapy. Immunity $\mathbf{2 7}$, 406-416 (2007)

182. De Jongh, F. E. et al. Survival and prognostic indicators in hepatitis B surface antigen-positive cirrhosis of the liver. Gastroenterology 103, 1630-1635 (1992).

\section{Acknowledgements}

We are grateful to the Wellcome Trust, the NIHR Biomedical Research Centre, Oxford, the Oxford Martin School, the UK Medical Research Council and the US National Institutes of Health (grant 5U19A082630-04) for support. We would like to thank also C. Wilson and A. Marchant for critical review of the manuscript.

Competing interests statement

The authors declare no competing financial interests.

\section{FURTHER INFORMATION}

Andrew J. Prendergast's homepage: http://www.icms.amul. ac.uk/Profiles/Paediatrics/Prendergast\%20Andrew.htm Paul Klenerman's homepage: http://www.ndm.ox.ac.uk/ principal-investigators/researcher/paul-klenerman Philip J. R. Goulder's homepage: http://www.paediatrics.ox ac.uk/research/professor-philip-goulder AVERT Worldwide HIV and AIDS Statistics: http://www.avert.org/worldstats.htm ClinicalTrials.gov: http://clinicaltrials.gov ALL LINKS ARE ACTIVE IN THE ONLINE PDF 